\title{
Precipitation and Mesoscale Convective Systems: Radiative Impact of Dust over Northern Africa
}

\author{
Irene Reinares MartíneZ AND JEAN-Pierre Chaboureau \\ Laboratoire d'Aérologie, Université de Toulouse, CNRS, UPS, Toulouse, France
}

(Manuscript received 20 March 2018, in final form 18 July 2018)

\begin{abstract}
The radiative effect of dust on precipitation and mesoscale convective systems (MCSs) is examined during a case of dust emission and transport from 9 to 14 June 2006 over northern Africa. The same method to identify and track different cloud types is applied to satellite observations and two convection-permitting simulations (with grid mesh of $2.5 \mathrm{~km}$ ), with and without the radiative effect of dust, performed with the MesoNH model. The MCSs produce most of the observed total precipitation (66\%), and the long-lived systems (lasting $6 \mathrm{~h}$ or more) are responsible for $55 \%$ of the total. Both simulations reproduce the observed distribution of precipitation between the cloud categories but differ due to the radiative effects of dust. The overall impacts of dust are a warming of the midtroposphere; a cooling of the near surface, primarily in the western parts of northern Africa; and a decrease in precipitation due to a too-low number of long-lived MCSs. The drop in their number is due to the stabilization of the lower atmosphere, which inhibits the triggering of convection. The long-lived MCSs are a little longer lived, faster, and more efficient in rainfall production when accounting for the dust-radiation interaction. This higher degree of organization is due to the larger convective available potential energy and an intensified African easterly jet. The latter is, in turn, a response to the variation in the meridional gradient of the temperature induced by the dust.
\end{abstract}

\section{Introduction}

Dust aerosols are recognized as having an important radiative effect on the atmosphere, notably over northern Africa, which has the largest sources of dust in the world (Engelstaedter et al. 2006). Dust aerosols scatter and absorb solar radiation and absorb and re-emit terrestrial radiation; this is the direct effect. Aerosol absorption has been shown to heat the air (Lemaitre et al. 2010) and cool the near surface by decreasing the solar radiation reaching the ground (Helmert et al. 2007). This leads to an increase in the low-level static stability (Tulet et al. 2008) and can modify the occurrence of cloud formation. These variations in temperature can, in turn, generate a dynamical response that brings the atmosphere to a new equilibrium, as well as changing the cloudiness and precipitation (the semidirect effect). Using the European Centre for Medium-Range Weather Forecasts (ECMWF) Integrated Forecast System (IFS) model, Tompkins et al. (2005) found an enhancement in the African easterly jet (AEJ; a midlevel thermal wind

Corresponding author: Dr. Irene Reinares Martínez, irene.reinares@ aero.obs-mip.fr modulated by the meridional gradient of temperature between the Gulf of Guinea and the Sahara) at the 5-day range when using a monthly climatology for dust instead of an annual mean. In addition, Chaboureau et al. (2007) showed an improvement in cloud cover over West Africa when using a prognostic dust scheme rather than a climatology. This highlights the importance of the description of dust in numerical models to correctly represent the weather in Africa. Nevertheless, the radiative effects of dust on the processes controlling precipitation remain largely unknown.

During the summertime, convective systems account for most of the precipitation in northern Africa (Janiga and Thorncroft 2014). In particular, large convective storms that become organized, mesoscale convective systems (MCSs), have been shown to generate up to $90 \%$ of the total precipitation in the Sahel (Mathon et al. 2002). Reinares Martínez and Chaboureau (2018) studied a dust outbreak from 9 to 14 June 2006 over northern Africa, which was previously documented by Flamant et al. (2009). They focused on the characteristics of long-lived MCSs (i.e., with a lifetime of at least $6 \mathrm{~h})$ and on the environmental conditions where they develop and found that the long-lived MCSs produce 
$55 \%$ of the total precipitation. A convection-permitting simulation with a resolution of $2.5 \mathrm{~km}$ was able to capture the degree of organization of the long-lived MCSs better than a run performed at a $20-\mathrm{km}$ resolution using a parameterization of the convection. Moreover, this organization was found to be highly controlled by the AEJ-induced low-level wind shear and to increase from east to west.

The aim of this paper is to examine the dynamical responses of the atmosphere to the radiative effect of dust and to analyze the changes induced in the precipitation. The radiative impact of dust on the organization of convection is also examined. This issue, to the best of the authors' knowledge, has not yet been addressed. To achieve this objective, we use the convectionpermitting simulation described in Reinares Martínez and Chaboureau (2018) and a second convectionpermitting simulation set up in the same manner, except with the radiative impact of the dust turned off. The simulation allowing the dust-radiation interaction includes schemes that account for the dust emission, transport, and deposition because simulating these processes is vital to represent the interaction of dust particles with radiation (Pérez et al. 2006; Chaboureau et al. 2007). During the period from 9 to 14 June 2006, dust was extensively emitted over northern Africa. The dust particles emitted from eastern sources in Chad and Sudan were then transported over West Africa (Flamant et al. 2009), where a large ensemble of airborne instruments allowed the analysis of the size distribution of the dust particles (Crumeyrolle et al. 2011) and of the radiative properties of the dust plumes, which were found to generate concomitant heating (Lemaître et al. 2010).

The remainder of the paper is organized as follows. The datasets and the method used to attribute rain to MCSs and to track them, which are described in detail in Reinares Martínez and Chaboureau (2018), are reviewed in section 2. The evaluation of the simulated dust, compared to the observations, is presented in section 3 . The atmospheric responses to both the direct and semidirect dust radiative effects are discussed in section 4 . In particular, it is shown that dust barely affects the relative contribution of different precipitating systems to the total rainfall over northern Africa. The impact on the MCSs and their precipitation production are analyzed in section 5. Finally, the conclusions are given in section 6 .

\section{Data and method}

\section{a. Model and observations}

Two simulations, NODUST and DUST [the latter called HiRes in Reinares Martínez and Chaboureau (2018)], are performed with the anelastic, nonhydrostatic model MesoNH (Lafore et al. 1998; Lac et al. 2018) version 5-1-3. Both simulations are convection permitting with a $2.5-\mathrm{km}$ horizontal grid spacing, 72 vertical levels up to a height of $30 \mathrm{~km}$, and a vertical grid spacing between 60 and $600 \mathrm{~m}$. The two simulations are run over a large domain of $3840 \times 7680 \mathrm{~km}^{2}$ (Fig. 1), which permits the representation of the dust emissions in Chad and Sudan and its transport (Flamant et al. 2009). The two simulations use approximately a third of a billion grid points. They are run from 0000 UTC 9 June to 0000 UTC 15 June 2006, with outputs every $3 \mathrm{~h}$ and initial and boundary conditions provided by the ECMWF operational analyses.

Both simulations share the same parameterizations, differing only in that DUST accounts for the radiative effect of dust. The surface fluxes are represented by the Surface Externalisée (SURFEX) scheme (Masson et al. 2013) in which natural land surfaces are handled by the Interaction between Soil, Biosphere, and Atmosphere (ISBA) scheme (Noilhan and Planton 1989). Both simulations use a 1.5-order closure scheme for the turbulence (Cuxart et al. 2000) and a parameterization of the dry thermals and shallow cumuli (Pergaud et al. 2009). In addition, they include a microphysical scheme for mixed-phase clouds (Pinty and Jabouille 1998), a subgrid statistical cloud scheme (Chaboureau and Bechtold 2005), the Rapid Radiative Transfer Model (Mlawer et al. 1997) for longwave radiation, and the two-stream scheme by Fouquart and Bonnel (1980) for shortwave radiation.

The dust prognostic scheme is described in Grini et al. (2006). It includes the Dust Entrainment and Deposition (DEAD) scheme (Zender et al. 2003), to which MesoNH provides the wind speed at a height of $10 \mathrm{~m}$, the soil moisture, and the roughness length. Dust is mobilized following Marticorena and Bergametti (1995) via a combination of saltation and sandblasting processes, and the horizontal flux of the dust particles can be computed. The vertical flux of the dust aerosols that will be injected into the atmosphere is calculated as the ratio of the horizontal flux and a sandblasting efficiency coefficient, which depends on the clay content of the soil. Once in the atmosphere, the time and space evolution of the dust is simulated in the Organic and Inorganic Lognormal Aerosols Model (ORILAM) scheme (Tulet et al. 2005). ORILAM considers three dust modes with a lognormal size distribution. Initially, the size distributions have median diameters of $0.078,0.64$, and $5.0 \mu \mathrm{m}$ and standard deviations of $1.75,1.76$, and $1.70 \mu \mathrm{m}$, respectively, as defined by Crumeyrolle et al. (2011). Finally, dust can undergo dry sedimentation and wet deposition to return to the surface. Regarding the 


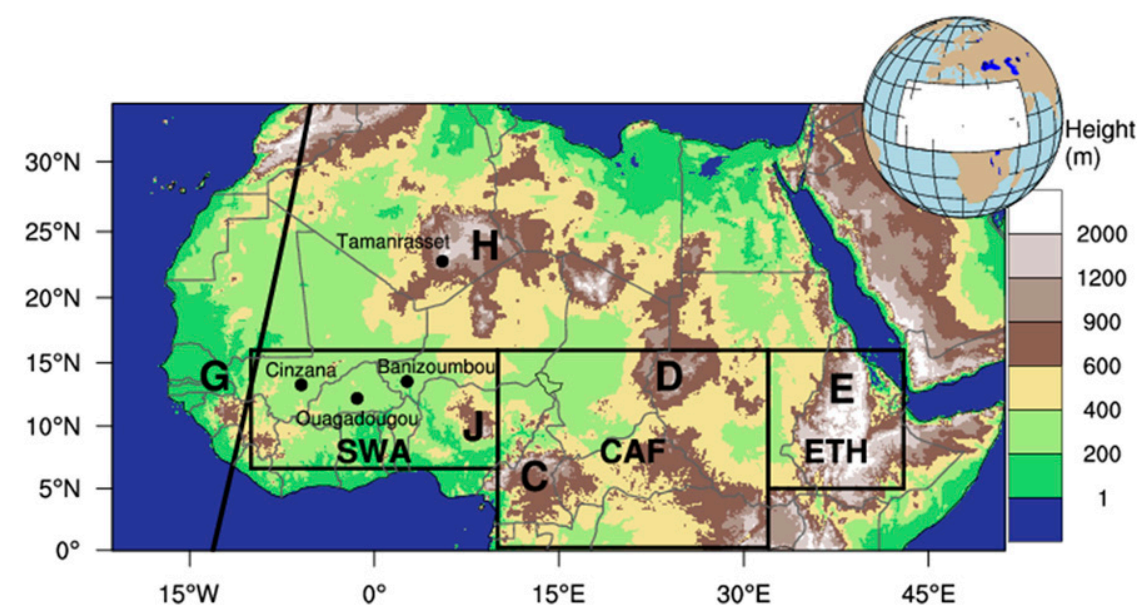

FIG. 1. Domain of simulation and analysis. In color is the altitude. Topographic features are the Guinea highlands $(\mathrm{G})$, the Hoggar Mountains $(\mathrm{H})$, the Jos Plateau (J), the Cameroon highlands (C), the Darfur Plateau (D), and the Ethiopian highlands (E). The black dots represent the location of the AERONET stations of Cinzana, Ouagadougou, Banizoumbou, and Tamanrasset analyzed in Fig. 2, and the black line represents the CALIPSO cross section of Fig. 4.

shortwave effect, the refractive indexes are 1.44800 $0.00292 i$ for wavelengths below $690 \mathrm{~nm}, 1.44023-0.00116 i$ for wavelengths between 690 and $1190 \mathrm{~nm}$, and 1.41163 $0.00106 i$ for wavelengths larger than $1190 \mathrm{~nm}$. For the absorption and re-emission of longwave radiation by dust, the standard formulation taken from the ECMWF model is used (Tulet et al. 2008). This formulation consists of adding a fraction of the aerosol optical depth to the longwave optical depth for $\mathrm{CO}_{2}$ and $\mathrm{H}_{2} \mathrm{O}$.

Two observation datasets are used to assess clouds and precipitation in the simulations: the Climate Prediction Center (CPC) globally merged 4-km-resolution brightness temperature (BT; Janowiak et al. 2001), merged using all available geostationary satellites, and the Tropical Rainfall Measuring Mission (TRMM) 3B42 version 7 3-hourly rainfall (Huffman et al. 2007), available in $0.25^{\circ}$ spatial resolution. Cloud systems are defined in terms of BT at $10.8 \mu \mathrm{m}$ (see section $2 \mathrm{~b}$ ), and the 3-hourly accumulated precipitation is associated with the cloud systems. From the model outputs, synthetic BTs corresponding to the Meteosat Second Generation (MSG) observations are computed offline using the Radiative Transfer for TIROS Operational Vertical Sounder (RTTOV) code version 8.7 (Saunders et al. 2005), following the method developed by Chaboureau et al. (2008). The gridded BT data ease the comparison with the model outputs, while the temporal sampling of the TRMM 3B42 product is convenient for the analysis of the diurnal cycle of precipitation, a feature that results in the TRMM 3B42 product being widely employed (e.g., Janiga and Thorncroft 2014; Zhang et al. 2016).
For the dust assessment, the aerosol optical depth (AOD) is provided on a $1^{\circ} \times 1^{\circ}$ regular latitudelongitude grid by Deep Blue collection version 6 from retrievals of the Moderate Resolution Imaging Spectroradiometer (MODIS; Hsu et al. 2004) on board the Aqua spacecraft. Aqua passes from south to north across the equator at approximately $1330 \mathrm{LT}$. The AOD is based on observations in the visible and ultraviolet spectra. The Deep Blue algorithm is convenient because it estimates the AOD over bright surfaces, such as the Sahara Desert, where dust emissions and concentrations are large.

The dust evaluation also takes advantage of the Aerosol Robotic Network (AERONET) sun photometers (Holben et al. 1998) at stations in Cinzana, Ouagadougou, Banizoumbou, and Tamanrasset. The sun photometers provide the aerosol properties with a time resolution of $15 \mathrm{~min}$ during the daytime. Here, we use the Ångström coefficient obtained from the 440- and 870-nm wavelengths and the AOD product at $440 \mathrm{~nm}$, a wavelength that lies within one of the three spectral windows (the one centered at $532 \mathrm{~nm}$ ) associated with the refractive indexes considered in DUST. The use of both MODIS Deep Blue and AERONET is convenient, because MODIS provides the regional distribution of the AOD in northern Africa, and the AERONET high-frequency local measurements allow the temporal characterization of the AOD. Note, however, that both products account for the AOD due to all types of aerosols, whereas the AOD computed in MesoNH is exclusively due to dust. 

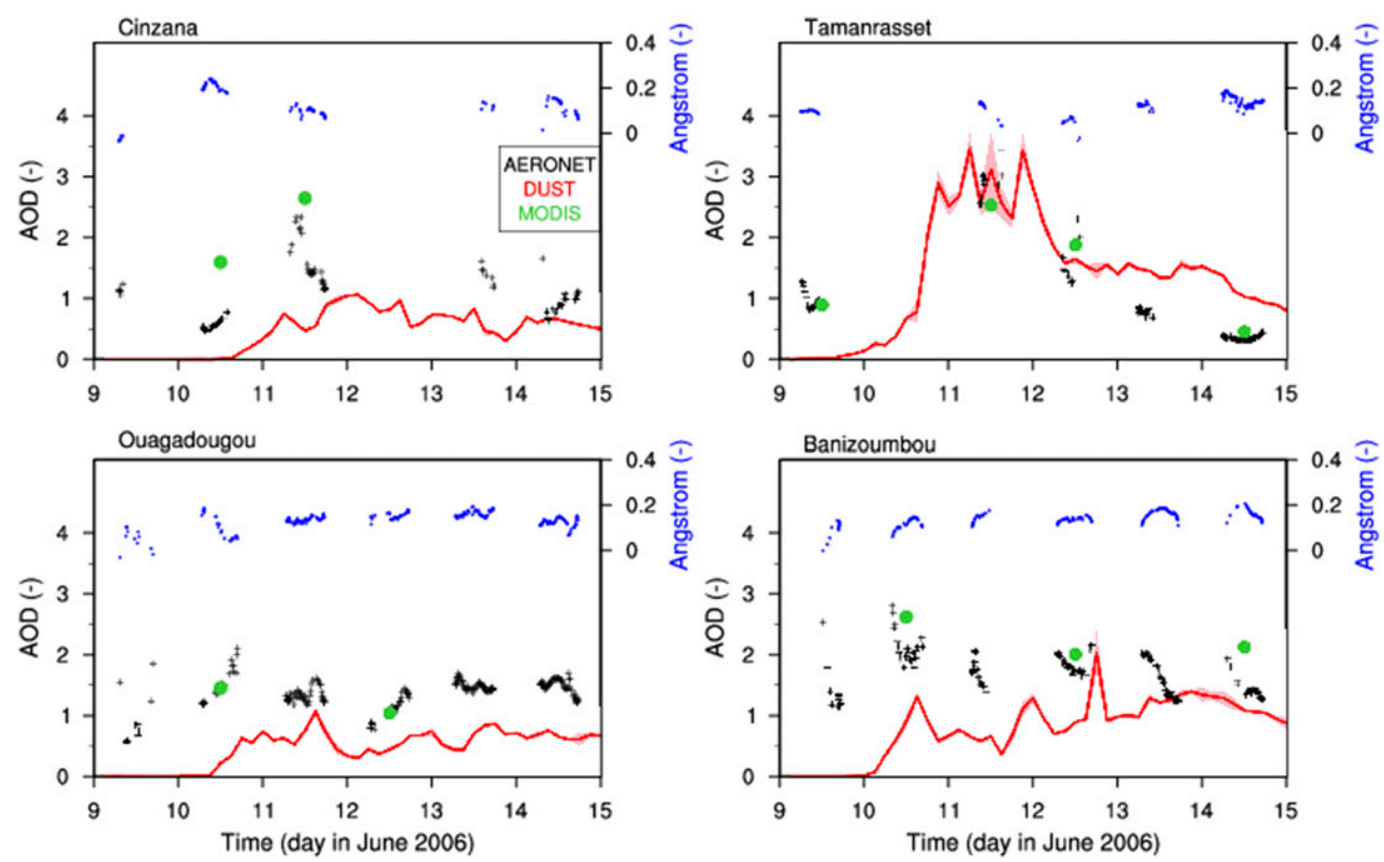

FIG. 2. Temporal evolution of the (left axis) AOD at $440 \mathrm{~nm}$ measured at the AERONET stations of Cinzana, Ouagadougou, Banizoumbou, and Tamanrasset (black crosses), measured by MODIS (green dots), and computed from the DUST simulation over a square of $0.3^{\circ} \times 0.3^{\circ}$ centered on the stations (red lines). The red-shaded contours correspond to the standard deviation of the simulated AOD values inside the squares. The Ångström coefficients (blue dots) are obtained from the 440- and 870-nm wavelengths at the sun photometers. The locations of the four stations are shown in Fig. 1.

This difference in aerosol type does not affect the conclusion because, as will be shown in Fig. 2, the Ångström coefficient values are small. This indicates a large particle size, and therefore that mineral dust was the predominant aerosol present over West Africa during the 9-14 June 2006 period.

To further assess the vertical distribution of dust, the backscatter coefficient at $532 \mathrm{~nm}$ from CALIOP on board CALIPSO (Winker et al. 2009) is employed. The CALIOP lidar provides observations during both the day and night. It has a very high sampling resolution, 30 and $335 \mathrm{~m}$ in the vertical and horizontal directions, respectively, but a poor temporal sampling of the same areas, with a 16-day repeat cycle due to its narrow swath. The CALIOP-derived product used here is only available after 13 June 2006. The simulated backscatter coefficients to be directly compared to the observed signals are computed in DUST with a lidar simulator integrated in the model. The latter computes the total backscatter coefficient from Rayleigh and Mie scattering, taking into account all the scattering particles predicted in the model, including dust, and following the assumptions made about their particle distribution and optical properties (Chaboureau et al. 2011).

\section{b. Tracking of MCSs}

The methodology used to attribute precipitation to cloud systems and to track MCSs is detailed in Reinares Martínez and Chaboureau (2018) and is briefly reviewed here. Two cloud categories are established: deep convective clouds (DCCs) with BT less than $230 \mathrm{~K}$ and cirrus anvil clouds (CACs) with BT ranging between 230 and $260 \mathrm{~K}$, to which the 3-hourly accumulated precipitation is attributed. For the observed clouds, the precipitation is taken from TRMM. In the BT distribution for DUST and NODUST, high (low) values of BT are more frequent (infrequent) than in the observations; therefore, the BT thresholds are adapted to the simulations such that each cloud category is equally represented over the 6-day period for the three datasets. Therefore, for both DUST and NODUST, the thresholds become 243 and $266 \mathrm{~K}$.

The DCC and CAC grid points sharing a common face are then aggregated into clusters. For each DCC cluster, vertical profiles of the thermodynamic variables are computed in the volume obtained when vertically projecting the envelope of the cluster. The variables are computed both at the time of detection and $6 \mathrm{~h}$ before at the same location to examine the characteristics of 
these DCCs and of the environment, respectively. For the observed DCC clusters, these profiles are extracted from the analyses and forecasts of the ECMWF, both with 6-h resolution, starting at 0000 and 0300 UTC, respectively.

The DCCs are then tracked through time using geographical overlapping, with a surface overlapping ratio of $20 \%$. The tracking is done only on DCC clusters with an effective diameter (the diameter of a circle with the same area as the cluster) larger than $120 \mathrm{~km}$ to ensure realistic trajectories despite the 3-h temporal lag between consecutive images. These tracked DCCs are called MCSs, and the others are called small DCCs. Finally, the MCSs are divided into long-lived MCSs (i.e., those that last at least $6 \mathrm{~h}$ ) and short-lived MCSs (i.e., those that last less than $6 \mathrm{~h}$ ). As in Reinares Martínez and Chaboureau (2018), three subregions covering the continental rainband are considered [Fig. 1; southern West Africa (SWA), central Africa (CAF), and Ethiopia (ETH)], with the aim of examining how dust radiatively impacts precipitation in each subregion.

\section{Assessment of dust}

\section{a. Time evolution at the AERONET stations}

The time series of the simulated AODs and those measured at $440 \mathrm{~nm}$ by AERONET from 9 to 14 June over four stations are shown in Fig. 2, together with the corresponding MODIS values and the 440-870-nm Ångström coefficient from AERONET. The stations at Cinzana, Ouagadougou, and Banizoumbou are located in SWA, while the station at Tamanrasset is located in the Sahara (their locations are depicted in Fig. 1). The Angström coefficient defines the spectral dependence of the AOD and provides information on the size of the particles that attenuate the radiation. The larger the Angström coefficient, the smaller the particles. The Ångström coefficient has values below 0.25 at Cinzana and Banizoumbou and values below 0.2 at Ouagadougou and Tamanrasset during the entire studied period. This corresponds well to the values below 0.4 measured on 13 June 2006 along $2^{\circ} \mathrm{E}$ from $10^{\circ}$ to $13^{\circ} \mathrm{N}$ between the stations of Ouagadougou and Banizoumbou (Crumeyrolle et al. 2011). In general, pure large dust has Ångström coefficient values of less than 0.4. Therefore, we can conclude that the values of AOD measured during this period are predominantly due to dust.

Among the AERONET stations, Cinzana records the lowest mean AOD value, approximately 1.11, due to its southwesternmost location, which places it the farthest from the dust-source regions. At Ouagadougou and

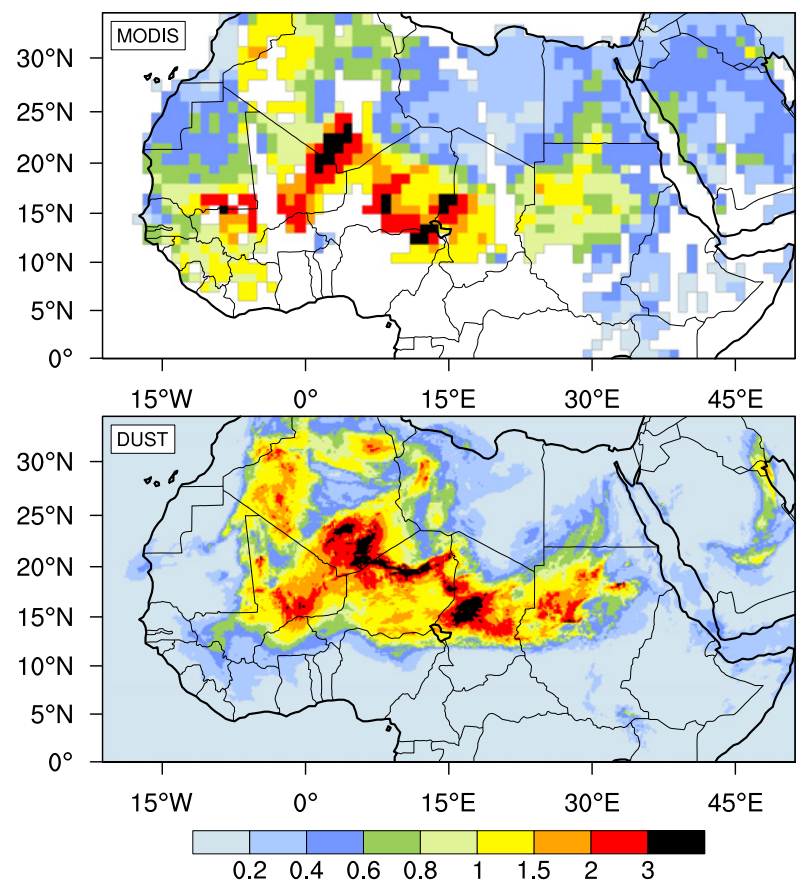

FIG. 3. AOD on 11 Jun 2006 for MODIS crossing the equator at 1330 UTC and for DUST at 1200 UTC. White areas indicate that no data are available.

Tamanrasset, the mean AOD values are very similar (1.30 and 1.31, respectively); however, while Ouagadougou has a rather flat series of values, a strong peak with a value larger than 3 is observed at Tamanrasset on 11 June. Note that an AOD of 3 indicates that the intensity of the radiation arriving at the sun photometer is only $5 \%$ of the incoming solar radiation at $440 \mathrm{~nm}$. Banizoumbou records the largest mean AOD value of 1.67; this station benefits from the transport pattern of dust from eastern sources. Using back trajectories, Flamant et al. (2009) showed that the AOD measured at Banizoumbou is due to dust that was emitted in Bodélé 2-3 days before, this source being active from 9 to 11 June. The AOD values for MODIS, when available, are largely consistent with those measured at the AERONET stations. The existing discrepancies may arise from the direct comparison of the coarse resolution $\left(1^{\circ} \times 1^{\circ}\right)$ of the MODIS product to the local characteristics of the sun photometer retrievals. The AOD values are generally underestimated by the model at the southern stations (Cinzana, Ouagadougou, and Banizoumbou). However, at Tamanrasset, the observed intense AOD peak is very well captured by DUST with values of approximately 3 . On 13 and 14 June, the simulated AOD values are overestimated. This is due to an extensive convective cold pool that developed at the border between southern Algeria and Mali in DUST (not shown). 
a) CALIOP

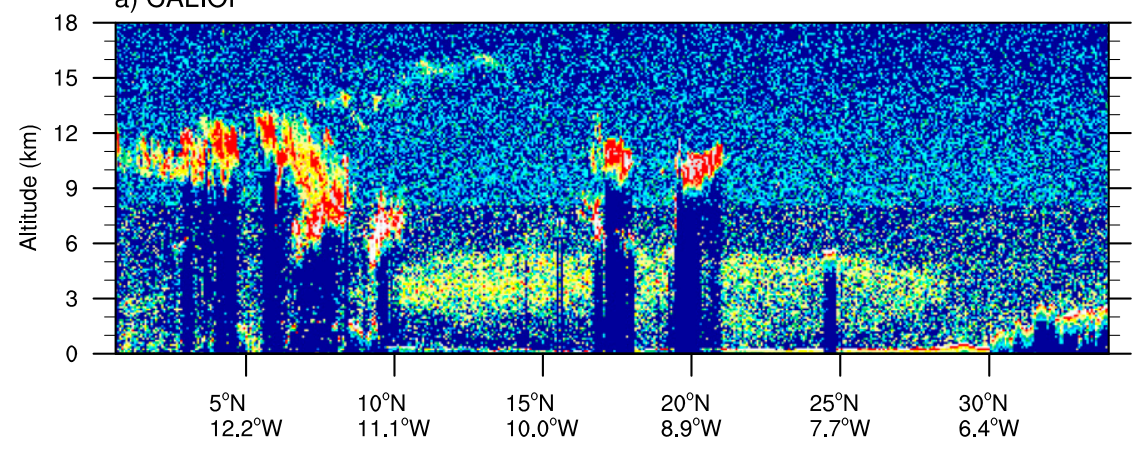

b) DUST

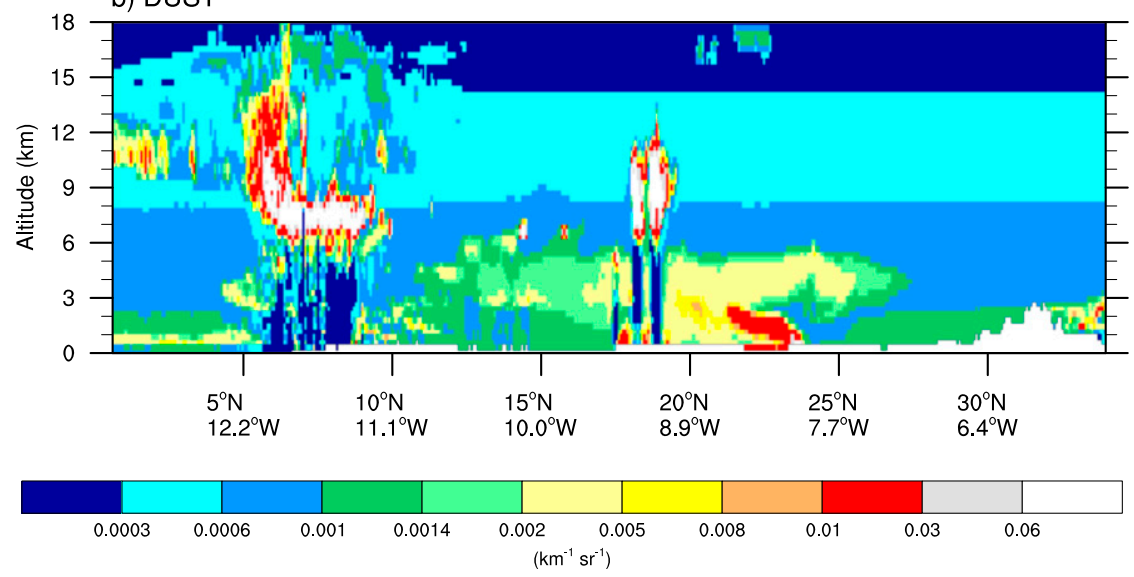

FIG. 4. Vertical cross section of the total backscatter coefficient at $532 \mathrm{~nm}$ on 14 Jun 2006 from (a) CALIOP at approximately 0200 UTC and (b) DUST at 0000 UTC. Its location is shown in Fig. 1.

\section{b. Spatial distribution of dust}

The horizontal distribution of AOD is shown for MODIS and DUST on 11 June 2006 (Fig. 3), when the AOD had its largest values over West Africa. East of $15^{\circ} \mathrm{E}$, the observed values of AOD larger than 1 are explained by the emissions over the eastern sources described by Flamant et al. (2009). They suggested that the emitted dust, mobilized by the Harmattan, reaches higher altitudes when passing above the monsoon flow at the ITD, being then transported within the AEJ over West Africa. West of $15^{\circ} \mathrm{E}$, dust is redistributed into the Saharan air layer (SAL) or sub-Saharan regions. The pattern of AOD values larger than 3 over southern Algeria corresponds to the AOD peak at Tamanrasset (Fig. 2). This peak and the pattern of the large AOD values (e.g., larger than 2) is explained by the arrival of the southerly sector of an African easterly wave that perturbed the mean flow of the AEJ (not shown) and transported the dust from the mean axis of the AEJ farther north, up to $25^{\circ} \mathrm{N}$. Retrievals of AOD are lacking near the Guinean coast due to the persistence of monsoonal clouds there. Both SWA and CAF have values of AOD larger than 2 north of $12^{\circ} \mathrm{N}$. In ETH, the AOD values are negligible because the emissions of the previous days occurred downstream of the AEJ. In the DUST simulation, the observed distribution and values of AOD are generally well reproduced, both over the source regions and over West Africa. In the simulation, the AOD also reaches values larger than 2 in SWA and CAF; however, in SWA, the AOD is underestimated over the Ivory Coast and southern Mali. Indeed, the simulated AOD is lower than the observed values in the continental regions west of $10^{\circ} \mathrm{W}$.

Figure 4 shows the vertical cross section of the total backscatter coefficient on 14 June 2006 retrieved by CALIOP at approximately 0200 UTC and obtained for DUST at 0000 UTC (only two CALIOP nighttime cross sections are available over West Africa during the studied period). The radiation at $532 \mathrm{~nm}$ strongly interacts with large particles such as clouds and dust via Mie scattering. In the absence of large particles, Rayleigh scattering is dominant throughout the atmosphere and becomes larger with decreasing altitude as 

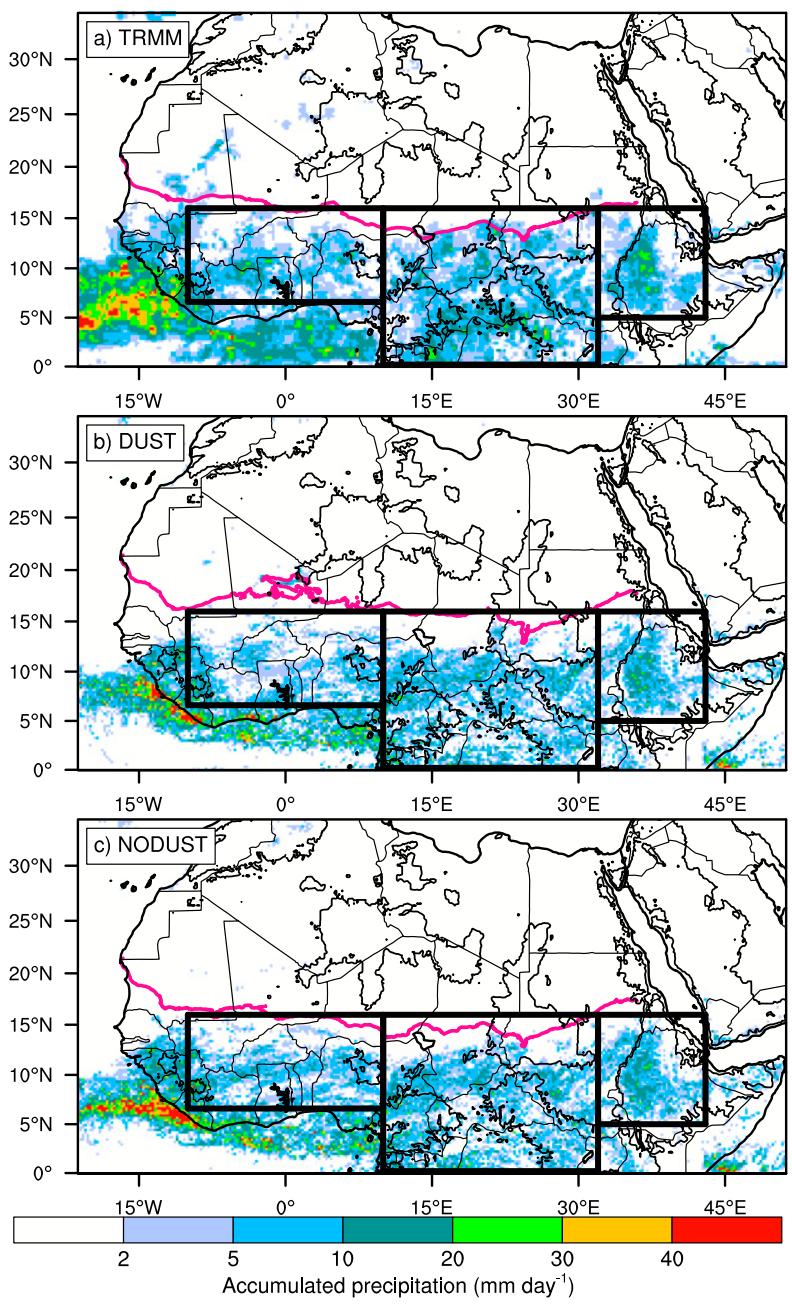

FIG. 5. Accumulated precipitation between 9 and 14 Jun 2006 for (a) TRMM, (b) DUST, and (c) NODUST. The pink line represents the mean position of the ITD, defined following Chaboureau et al. (2016). The solid black lines represent the orography at an altitude of $600 \mathrm{~m}$, and the black boxes delimit the three subregions.

the concentration of air molecules increases. For CALIOP, backscatter coefficient values larger than $10^{-2} \mathrm{~km}^{-1} \mathrm{sr}^{-1}$ correspond to high-level clouds south of $10^{\circ} \mathrm{N}$ and near $15^{\circ}$ and $20^{\circ} \mathrm{N}$. Between $25^{\circ}$ and $30^{\circ} \mathrm{N}$, these large values may be related to dust emissions. A dust plume, characterized by backscatter coefficient values between $10^{-3}$ and $10^{-2} \mathrm{~km}^{-1} \mathrm{sr}^{-1}$, is located between $10^{\circ}$ and $28^{\circ} \mathrm{N}$ above the residual boundary layer and extends up to $6 \mathrm{~km}$, to the altitude of the SAL. High clouds south of $10^{\circ} \mathrm{N}$ are well located in DUST and span the same range of altitudes as observed. DUST reproduces the vertical extent and meridional location of the dust plume well.

To assess the dust, the simulated optical depth and backscatter coefficient were compared to the AERONET measurements and MODIS retrievals and the CALIOP observations, respectively. Good agreement is found for the regional distribution of the dust and its vertical stratification, and the DUST simulation is able to capture the entire range of the observed AOD values. Therefore, the DUST simulation is sufficiently realistic to address the radiative effects of dust on the atmosphere.

\section{Impact of dust on the atmosphere}

\section{a. Distribution of precipitation}

The accumulated precipitation is shown in Fig. 5 for the TRMM observations and the two simulations. The mean position of the intertropical discontinuity (ITD) is superimposed. It is defined as the continental zone where the water vapor mixing ratio at the surface is equal to $10 \mathrm{~g} \mathrm{~kg}^{-1}$ (taken from the ECMWF analysis) that corresponds to $14^{\circ} \mathrm{C}$ dewpoint temperature, following Chaboureau et al. (2016). Precipitation is observed from the eastern Atlantic to the Ethiopian highlands south of $15^{\circ} \mathrm{N}$. Over the ocean, the highest precipitation values are located offshore the coasts of Guinea and Sierra Leone. Over the continent, precipitation primarily lies within the subregions of SWA, $\mathrm{CAF}$, and ETH. In these subregions, the highest precipitation values are observed to the western side of the Jos Plateau and over the mountain-devoid areas of Burkina Faso and the Ivory Coast, in the foothills of the Darfur Plateau and Cameroon Mountains, and over the Ethiopian highlands, respectively. In the ECMWF analysis, the ITD is located at around $15^{\circ} \mathrm{N}$ from the western coast to Sudan and reaches farther north in SWA than in CAF.

Both DUST and NODUST reproduce the observed distribution of precipitation. There are, however, several differences from the observations, especially over the coastal regions and the eastern Atlantic, where the meridional extent of the precipitation is reduced in the simulations. Over land, the precipitation has slightly lower values than those observed over the Darfur Plateau and the Cameroon Mountains. In terms of continental precipitation, the two simulations differ the most over SWA, where DUST produces less precipitation than NODUST. The position of the ITD varies between the two simulations over SWA and CAF. There, it reaches higher latitudes for DUST, suggesting differences in the regional circulations between the simulations.

The partition of the total precipitation into different cloud categories (Fig. 6) is performed by associating the 3-hourly accumulated precipitation, with the clusters corresponding to each cloud category. The long-lived MCSs are the primary precipitation producers, being 


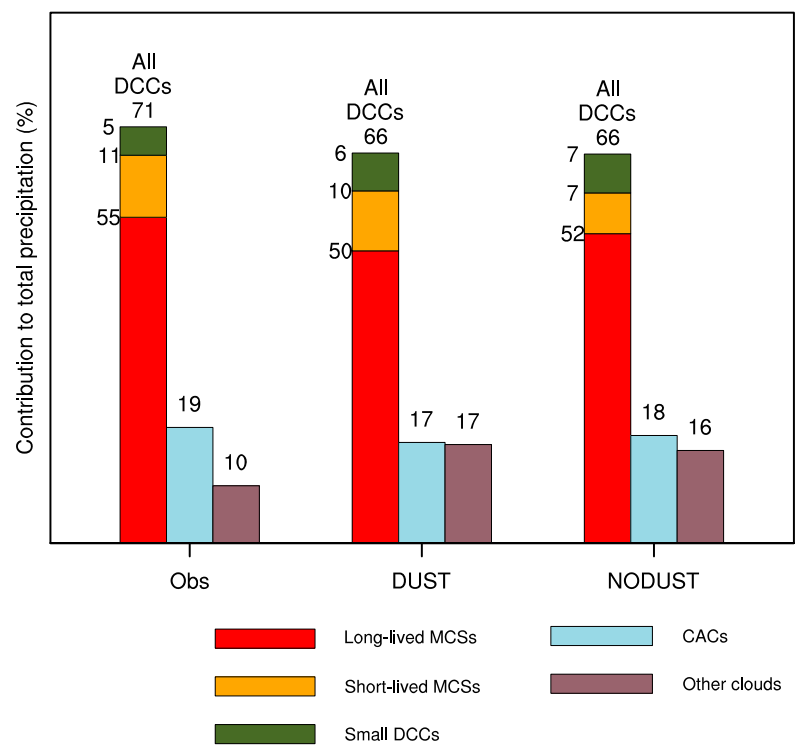

FIG. 6. Contribution of all the DCCs (long-lived and short-lived MCSs and small DCCs), CACs, and clouds other than DCCs or CACs to the total precipitation over the simulation domain between 9 and 14 Jun 2006 for the observations and the simulations.

responsible for $55 \%$ of the observed total precipitation. This contribution, as well as those from short-lived MCSs $(11 \%)$ and small DCCs $(5 \%)$, is part of the precipitation due to all DCCs $(71 \%)$. The rest $(29 \%)$ is due to clouds other than DCCs. DUST and NODUST reproduce this distribution well, especially for the major precipitation producers, with $50 \%$ and $52 \%$ of precipitation due to long-lived MCSs, respectively, and $66 \%$ due to all DCCs for both simulations. Overall, the relative contribution of different cloud types to precipitation is impacted little by the dust-radiation interaction. We further investigate how the atmosphere is modified and the implications for the net rainfall production by the long-lived MCSs, which explain the largest part of precipitation.

\section{b. Temperature and modulation of the AEJ and the monsoon flow}

The vertical structure of the temperature is expected to vary under the effect of dust, primarily due to the latter's vertical layering and radiative properties that lead to an attenuation of the incoming radiation. The AEJ is a thermal wind [i.e., its (zonal) wind speed changes with altitude proportionally to the temperature change with latitude]; therefore, the AEJ should also be impacted by the radiative effect of dust. To analyze the modulation of the AEJ with dust, we examine the mean values of the temperature and wind speed for DUST and NODUST. In addition, we examine these quantities from the ECMWF analyses to compare to the simulated variables in terms of their magnitude, although we assume that errors can be associated to the analysis, partly due to the scarcity of observations in the region. In Fig. 7, the left panel shows the wind speed at $600 \mathrm{hPa}$, the level where the speed of the AEJ is maximum. The AEJ is located near $12^{\circ} \mathrm{N}$ and corresponds to wind speeds larger than $10 \mathrm{~m} \mathrm{~s}^{-1}$ extending from ETH to SWA. In the ECMWF analyses, the AEJ core has speeds larger than $16 \mathrm{~m} \mathrm{~s}^{-1}$ and extends meridionally from $8^{\circ}$ to $14^{\circ} \mathrm{N}$ and zonally from $15^{\circ} \mathrm{W}$ to $15^{\circ} \mathrm{E}$. In the two simulations, the meridional extent of the AEJ is well captured; however, its zonal extent is slightly reduced, compared to that in the ECMWF analyses. The AEJ core is the least intense for NODUST, especially over SWA. The right panel in Fig. 7 shows the vertical structure of the potential temperature and the wind speed across latitude, both averaged between $10^{\circ} \mathrm{W}$ and $10^{\circ} \mathrm{E}$, corresponding to the limits of SWA, where the AOD and the speed of the AEJ are the largest. In the ECMWF analyses, the potential temperature has a pronounced gradient at the surface that increases from $298 \mathrm{~K}$ at the equator in the Gulf of Guinea to $314 \mathrm{~K}$ between $20^{\circ}$ and $25^{\circ} \mathrm{N}$ in the Sahara. The high surface temperature and associated sensible fluxes over the Sahara generate strong vertical mixing, resulting in a thick Saharan boundary layer characterized by a low vertical gradient of the potential temperature. This gradient is much larger over the Gulf of Guinea. As a consequence, from the surface to approximately $4-\mathrm{km}$ altitude, the potential temperature increases with latitude and decreases with latitude above. This leads to an increase in the wind speed with height until an altitude of $4 \mathrm{~km}$, where the AEJ reaches its maximum speed, and then a decrease beyond that. Near 4-km altitude and $12^{\circ} \mathrm{N}$, the AEJ has a speed of $17 \mathrm{~m} \mathrm{~s}^{-1}$. In the simulations, the potential temperature between the altitudes of 3 and $5 \mathrm{~km}$ and north of $10^{\circ} \mathrm{N}$ differs with respect to the ECMWF analyses. In DUST (NODUST), the atmosphere is warmer (cooler) there. Accordingly, the strength and altitude of the AEJ also differ. The overall effect is an AEJ that is enhanced and slightly higher in altitude $(\sim 500 \mathrm{~m})$ in DUST and an AEJ that is lessened $\left(1-2 \mathrm{~m} \mathrm{~s}^{-1}\right)$ and lower in altitude $(\sim 100 \mathrm{~m})$ in NODUST with respect to the ECMWF analyses.

The radiative impact of dust on the temperature and wind speed is further investigated over SWA. The vertical cross section of the difference in the temperature and wind speed between DUST and NODUST is shown in Fig. 8. The difference in the water vapor mixing ratio, as well as the dust extinction for DUST, is also shown. At the top of the dense dust plume (at an altitude of $5 \mathrm{~km})$, the extinction coefficient is $0.06 \mathrm{~km}^{-1}$, which 

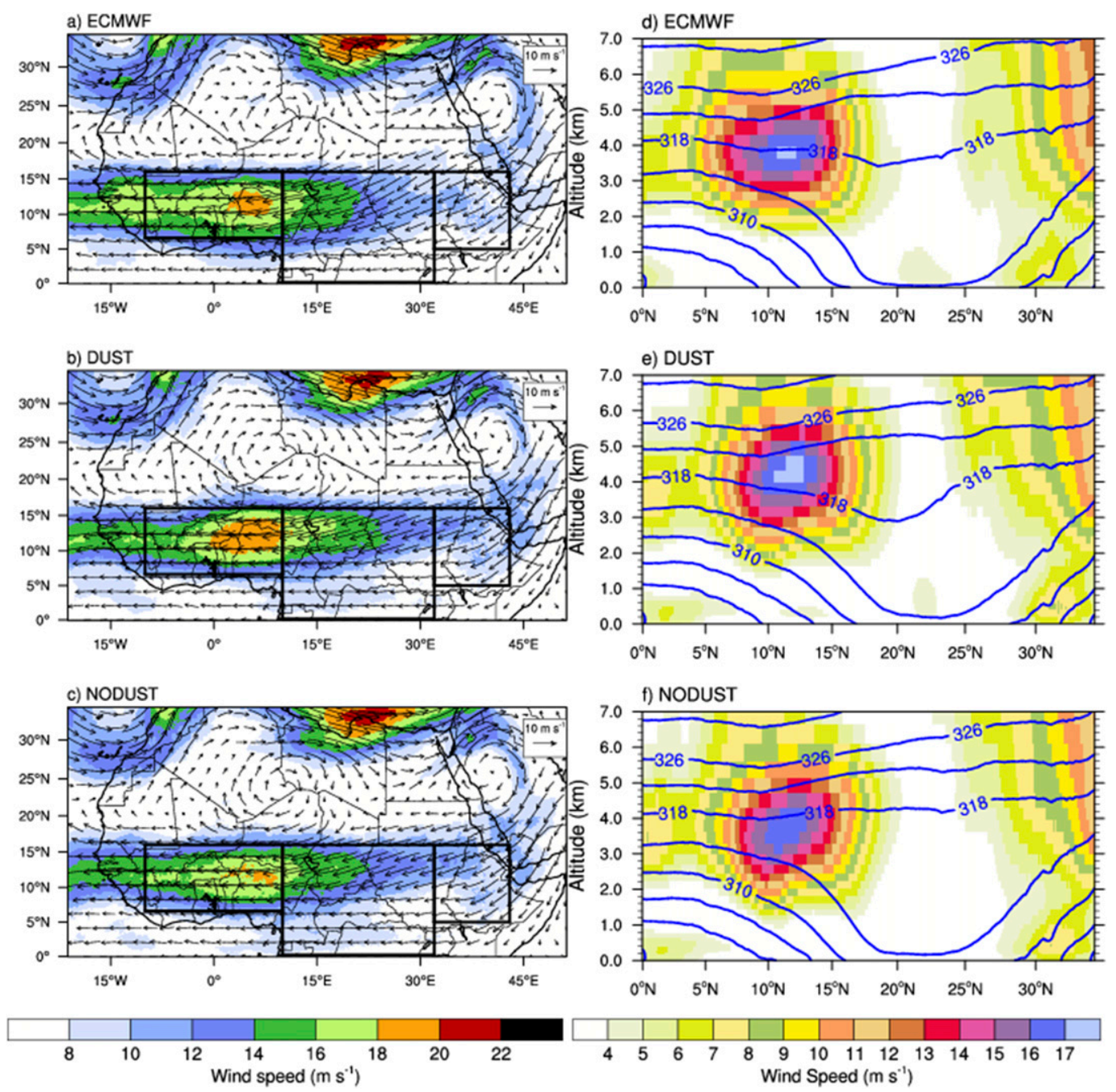

Wind Speed $\left(\mathrm{m} \mathrm{s}^{-1}\right)$ ) 14 15 16 17

FIG. 7. (left) Wind speed at $600 \mathrm{hPa}$ for (a) ECMWF, (b) DUST, and (c) NODUST. (right) Potential temperature
blue lines every $4 \mathrm{~K}$ ) and wind speed (colors) averaged between $10^{\circ} \mathrm{W}$ and $10^{\circ} \mathrm{E}$ for (d) ECMWF, (e) DUST, and (f) NODUST. The fields are averaged over the period of 9-14 Jun 2006.

quickly drops to near zero at higher levels in the absence of dust. The obtained value of $0.06 \mathrm{~km}^{-1}$, averaged zonally and in time in DUST, is consistent with the value of $0.05 \mathrm{~km}^{-1}$ derived from airborne lidar measurements at the top of the dust layer on 13 and 14 June 2006 (Lemaitre et al. 2010). A net increase of more than $1.3 \mathrm{~K}$ during the 6-day period is found for DUST at altitudes of $3-5 \mathrm{~km}$. This increase is consistent with the average warming of $1.5-4 \mathrm{~K}$ found by Lemaitre et al. (2010). These values are larger because they are estimated during the daytime, when the shortwave absorption by dust and the consequent increase in the temperature occur. The decrease in potential temperature by $0.3-$ $0.9 \mathrm{~K}$ north of $12^{\circ} \mathrm{N}$ for DUST with respect to NODUST may be explained through two mechanisms: first, a reduction in the intensity of the radiation arriving at the near surface because of the dust absorption aloft; and second, an enhanced cold monsoon flow, in agreement with the mean position of the ITD, which is displaced northward in DUST with respect to NODUST, as seen from Fig. 5. Midlevel warming and surface cooling are also found over CAF and ETH but with much lower temperature variations (not shown).

The change in the horizontal and vertical gradients of the potential temperature impacts the wind speed considerably. The increase in the wind speed when accounting for dust is as large as $2 \mathrm{~m} \mathrm{~s}^{-1}$ at an altitude of $5 \mathrm{~km}$ between $9^{\circ}$ and $15^{\circ} \mathrm{N}$, corresponding to the modulation of the AEJ. A moistening occurs in DUST below the warmed midlevel layer, with an increase in the water vapor mixing ratio of more than $1 \mathrm{~g} \mathrm{~kg}^{-1}$ in the lowest $2 \mathrm{~km}$, concomitant with the decrease in potential temperature. 

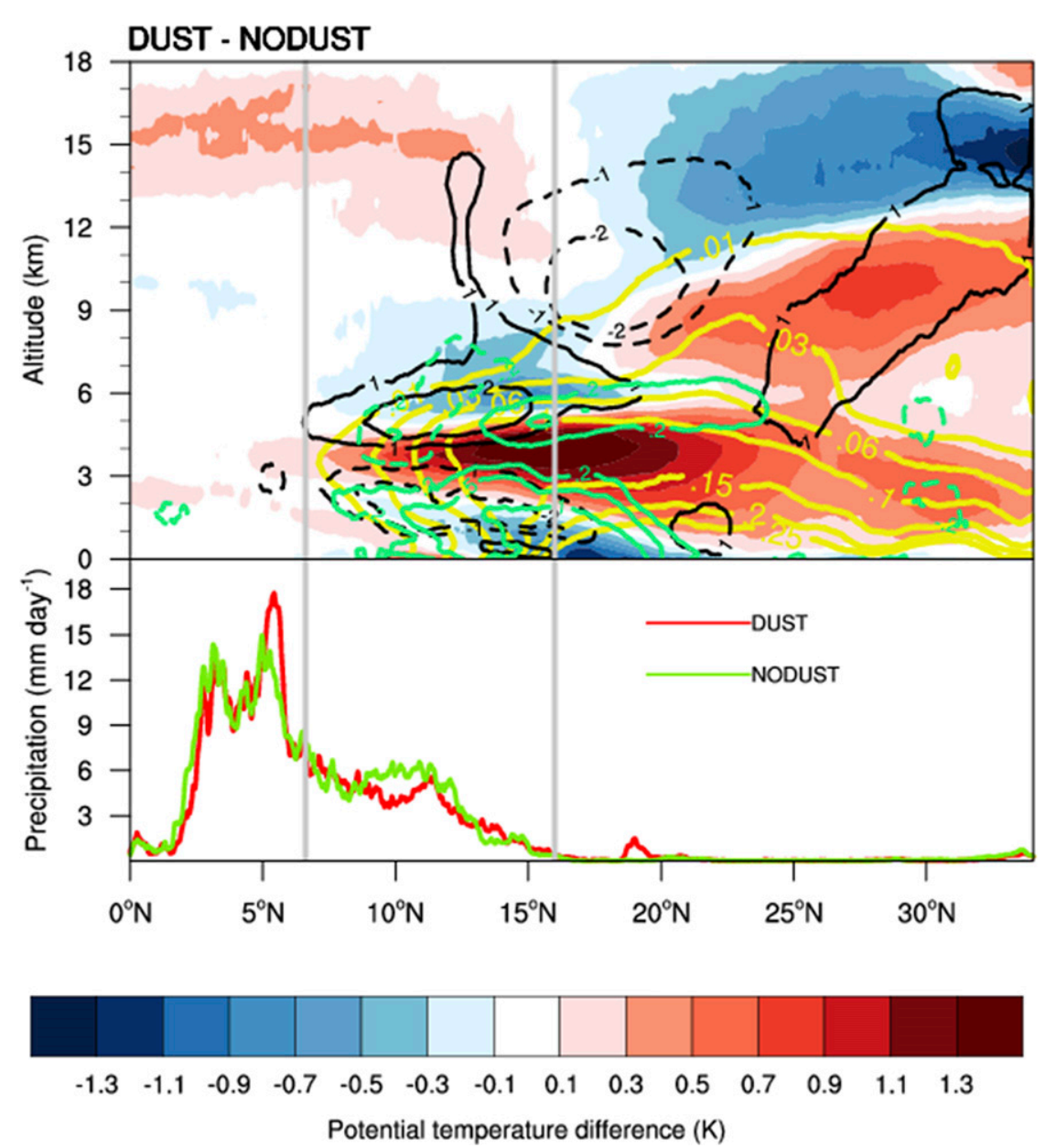

FIG. 8. (top) Altitude-latitude cross section of the 6-day mean difference in $\theta(\mathrm{K})$, wind speed ( $\mathrm{m} \mathrm{s}^{-1}$; black isocontours), and water vapor mixing ratio $\left(\mathrm{g} \mathrm{kg}^{-1}\right.$; blue-green isocontours) between DUST and NODUST. The yellow isocontours represent the mean dust extinction $\left(\mathrm{km}^{-1}\right)$ coefficient in DUST and correspond to values of $0.01,0.03,0.06,0.1,0.15,0.2$, and 0.25 . All the variables are averaged between $10^{\circ} \mathrm{W}$ and $10^{\circ} \mathrm{E}$, the longitudinal limits of SWA. The gray lines depict the meridional limits of SWA. (bottom) The 6-day mean precipitation between $10^{\circ} \mathrm{W}$ and $10^{\circ} \mathrm{E}$.

Finally, precipitation in DUST diminishes with respect to NODUST near $10^{\circ} \mathrm{N}$ in SWA, but slightly increases near $20^{\circ} \mathrm{N}$, as also seen in Fig. 5 .

The relationship between the cooling of the low atmosphere and the monsoon flow is further analyzed. The temporal evolution of the potential temperature at the surface, precipitation, and mean position of the ITD for DUST and NODUST over SWA is shown in Fig. 9. The AOD is also presented for DUST. Both the potential temperature and the ITD experience a strong diurnal variation, as the monsoon flow intensifies during the night and morning hours, penetrating farther north, when turbulent fluxes in the boundary layer are much reduced. For example, on 9 June, potential temperature at $15^{\circ} \mathrm{N}$ decreases from 304 to $300 \mathrm{~K}$ from 0600 to
1200 UTC in both DUST and NODUST, and the ITD reaches its northernmost diurnal position slightly before 1200 UTC. The latter retreats southward from 1200 to 1800 UTC, accompanied by an increase in temperature. These diurnal variations appear for both simulations during the whole period. They are, however, less pronounced for DUST after 11 June. From that day onward, the ITD shows a northward migration from around $15^{\circ} \mathrm{N}$ on $9 / 10$ June to $19^{\circ} \mathrm{N}$ by 15 June, whereas the ITD remains at $15^{\circ} \mathrm{N}$ for NODUST during the 6-day period. For DUST, this northward march is time related with the increase in AOD over West Africa, and particularly over the northern parts of SWA, where AOD reaches values above 1 from 11 June onward. Differences in potential temperature between DUST and NODUST 

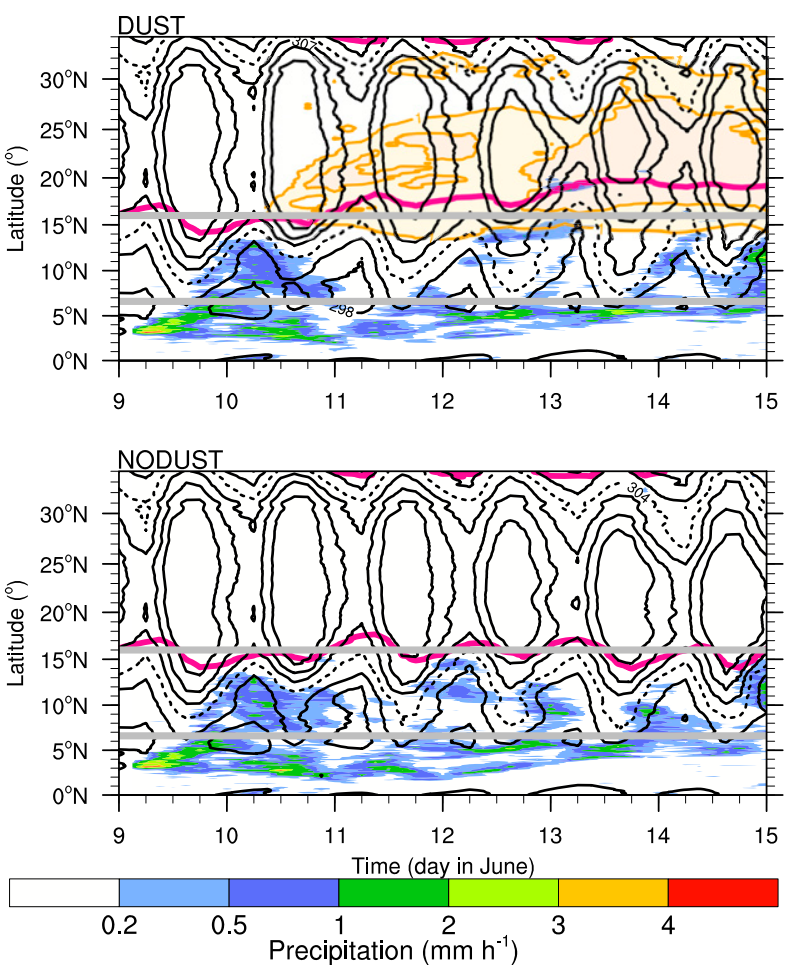

FIG. 9. Latitude-time diagrams for (top) DUST and (bottom) NODUST of the position of the ITD (pink), the total precipitation (shaded colors), the potential temperature at the surface (black lines), and the AOD (orange lines and shades; only for DUST). The values of the isotherms are 298, 301, 304 (dashed), 307, 310, and $313 \mathrm{~K}$, and the isocontours of AOD are 1.0 and 1.5. All the variables are averaged between $10^{\circ} \mathrm{W}$ and $10^{\circ} \mathrm{E}$, the longitudinal limits of SWA. The gray lines depict the meridional limits of SWA.

occur, with the greatest values on 13 and 14 June. North of $12^{\circ} \mathrm{N}$, there is cooling for DUST. For example, at 0600 UTC 13 June, the potential temperature for DUST at $15^{\circ} \mathrm{N}$ is $301 \mathrm{~K}$, whereas for NODUST, it is $303 \mathrm{~K}$. Over the Sahara, between $20^{\circ}$ and $25^{\circ} \mathrm{N}$, cooling is also evident. These 2 days correspond with the ITD reaching $19^{\circ} \mathrm{N}$, its northernmost position, when the AOD is larger than 1.5 for DUST. As a consequence, the monsoon flow plays an important role in the near-surface cooling under the radiative effect of dust and in transporting moisture farther north for DUST. This increased moisture explains precipitation appearing farther inland for DUST than for NODUST. The precipitation pattern near $20^{\circ} \mathrm{N}$ between 0000 and 0600 UTC for DUST is produced by a long-lived MCS (not shown) and may further favor the displacement of the ITD through its convective cold pool; this type of convection-ITD interaction has been previously reported (Flamant et al. 2007).

In summary, the temperature variations in the presence of dust, which are the largest over SWA, lead to an enhancement of the AEJ and monsoon flow and to the stabilization of the low atmosphere. As shown below, the latter changes the nature of the convective activity and ultimately explains the reported decrease in precipitation.

\section{c. CAPE and CIN}

Convective available potential energy (CAPE) and convective inhibition (CIN) are two variables commonly used to characterize the conditions that are favorable for moist convection. We analyze the most unstable CAPE and its associated CIN because these variables respond to changes in the vertical profiles of the atmosphere. For the three subregions, the bidimensional histograms of the individual values of CAPE and CIN are shown for the two simulations in Fig. 10. First, large regional differences in the shapes of the distributions are found between ETH and the other two subregions, regardless of the simulation. The values of CAPE are much lower in ETH (below $1000 \mathrm{~J} \mathrm{~kg}^{-1}$ ) than in SWA or CAF (between 1000 and $2000 \mathrm{~J} \mathrm{~kg}^{-1}$ ). Second, differences between DUST and NODUST are found primarily for SWA and CAF. In SWA, there are fewer grid points with values of CAPE lower than $600 \mathrm{~J} \mathrm{~kg}^{-1}$ for DUST than for NODUST; however, larger values between 1000 and $2000 \mathrm{~J} \mathrm{~kg}^{-1}$ occur more frequently. The larger values of CAPE occur for the entire range of CIN values, from 0 to $15 \mathrm{~J} \mathrm{~kg}^{-1}$. To have access to CAPE, an air parcel must have a vertical wind speed greater than $1.4 \mathrm{~m} \mathrm{~s}^{-1}$ below the level of free convection to overcome a CIN of $1 \mathrm{~J} \mathrm{~kg}^{-1}$. Thus, values of CIN greater than $1 \mathrm{~J} \mathrm{~kg}^{-1}$ lead to an inhibition of convection, because updrafts do not generally have vertical wind speeds large enough in the lower levels of the atmosphere to overcome such values of CIN. Therefore, the lower part of the joint distribution is more representative of convection. The number of grid points with a CIN lower than $1 \mathrm{~J} \mathrm{~kg}^{-1}$ and a CAPE lower than $1000 \mathrm{~J} \mathrm{~kg}^{-1}$ represents $6 \%$ of the total in DUST and $8 \%$ of the total in NODUST. This means that the triggering of weak convection is expected to occur more frequently for NODUST than for DUST. Conversely, $17 \%$ of the grid points for DUST and $14 \%$ of the grid points for NODUST have CIN values lower than $1 \mathrm{~J} \mathrm{~kg}^{-1}$ and CAPE values between 1000 and $2000 \mathrm{~J} \mathrm{~kg}^{-1}$. This argument holds for both SWA and CAF, where convection will likely be more intense for DUST than for NODUST. Grid points with values of CIN likely to permit convection have higher values of CAPE.

\section{Impact of dust on long-lived MCSs}

\section{a. Precipitation and propagation}

The impact of dust on the precipitation produced by long-lived MCSs is investigated because they contribute 

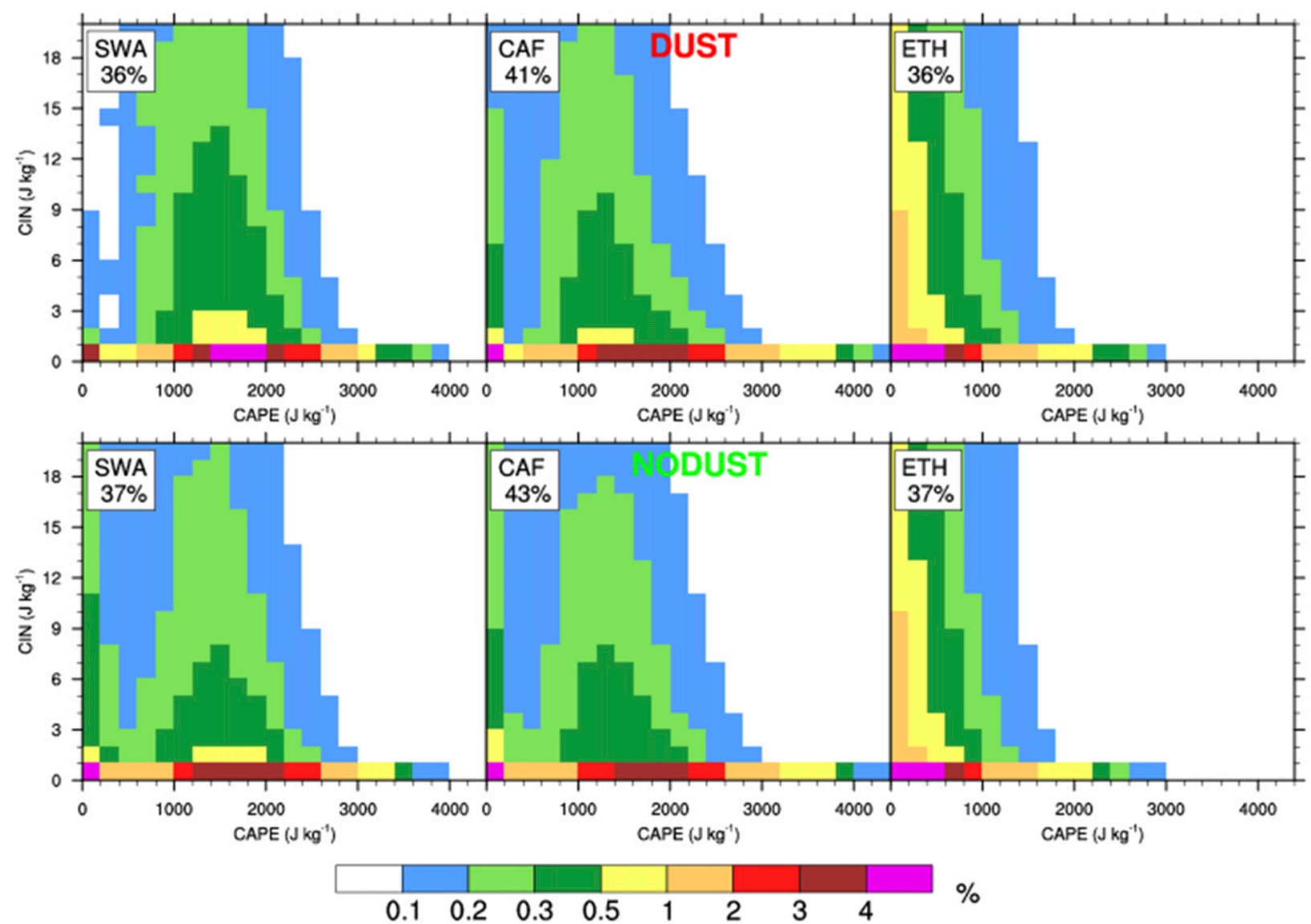

FIG. 10. Bidimensional histograms of CAPE and CIN for (top) DUST and (bottom) NODUST and for (left) SWA, (middle) CAF, and (right) ETH. The grid points with CAPE or CIN equal to $0 \mathrm{~J} \mathrm{~kg}^{-1}$ and those with CIN larger than $20 \mathrm{~J} \mathrm{~kg}^{-1}$ were discarded. The number in the label indicates the percentage of the grid points remaining.

to more than half of the total accumulated rainfall. The difference in precipitation between DUST and NODUST is shown in Fig. 11. The insert represents the difference in the total precipitation and in the precipitation due to long-lived MCSs for each subregion. Overall, DUST produces $10 \%$ less precipitation than NODUST. Changes in precipitation over the eastern Atlantic suggest a northward shift of the intertropical convergence zone, which is consistent with the northward displacement of the monsoon over land. Continental precipitation accounts for $39 \%$ of the $10 \%$ drop in DUST. SWA is the subregion contributing the most to this precipitation decrease over land. This is explained by the long-lived MCSs. Indeed, in SWA, the negative values of the rain difference appear spatially as elongated strips, corresponding to southwestwardpropagating long-lived MCSs, which is consistent with the trajectories shown in Fig. 12 below. Over CAF and $\mathrm{ETH}$, the negative values are distributed in a more fragmented manner, and the decrease in the rainfall is due to precipitating systems other than long-lived MCSs. The latter produce nearly the same amount of precipitation in DUST and NODUST over CAF and ETH.

These long-lived MCSs propagate westward in both the observations and the simulations (Fig. 12). Over the continent, they tend to be detected for the first time over the Ethiopian highlands in ETH, in the fringes of the Darfur Plateau and Cameroon highlands in CAF, and near the Jos Plateau and Guinea highlands in SWA. In SWA, several trajectories of long-lived MCSs also start over the plains west of the Jos Plateau, especially for NODUST, which generally has a much larger number of long-lived MCSs (101) than those observed (62) or simulated by DUST (84). The difference in the number of long-lived MCSs between DUST and NODUST is more pronounced over SWA and is related to the stabilization of the low-level atmosphere in DUST as a consequence of the midlevel warming and near-surface cooling when accounting for dust. 


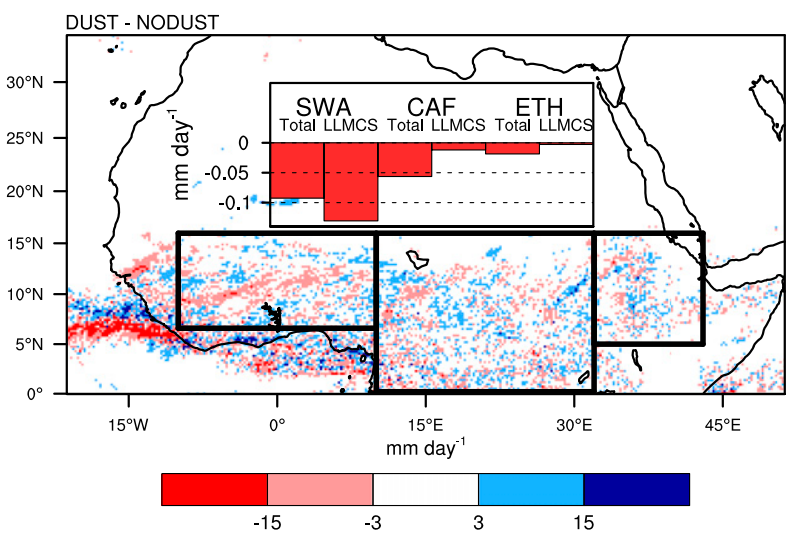

FIG. 11. Difference in the accumulated precipitation between DUST and NODUST. The inset shows the difference in the total precipitation and the precipitation due to long-lived MCSs over SWA, CAF, and ETH.

The number, size, and propagation characteristics of the observed and simulated long-lived MCSs are further investigated for the three subregions (Fig. 13). Each long-lived MCS is assigned to the subregion where it spends most of its lifetime, and the mean zonal speed of each long-lived MCS is calculated from the locations of its center of mass at its first and last detections. The observed long-lived MCSs increase their effective diameters, lifetimes, precipitation intensities, and zonal speeds from east to west. They are the most organized and fastest over SWA. There, they have a mean diameter of $600 \mathrm{~km}$, a lifetime of approximately $20 \mathrm{~h}$, and a precipitation rate of more than $1000 \mathrm{~mm} \mathrm{~h}^{-1}$. Finally, their zonal propagation speed is $18 \mathrm{~m} \mathrm{~s}^{-1}$.

For DUST and NODUST, these characteristics are poorly represented over SWA. The most pronounced differences with respect to the observations over SWA are the effective diameter and lifetime of the long-lived MCSs, which are half the observed values. Moreover, the long-lived MCSs are too slow, and the precipitation production is less than half the observed values. As a result, the increase in the degree of organization of the long-lived MCSs from ETH to SWA is not fully represented by DUST.

For NODUST, long-lived MCSs over SWA are slower (by $3 \mathrm{~m} \mathrm{~s}^{-1}$ ), shorter lived (by $2 \mathrm{~h}$ ), and less efficient in precipitation production (by $50 \mathrm{~mm} \mathrm{~h}^{-1}$ ) than for DUST. The most striking result is the number of long-lived MCSs, which is much larger (3 times more). This explains why, for DUST, precipitation is generally suppressed over SWA, as shown in Fig. 11. For DUST, the less-frequent triggering of convection over SWA may lead to an excess of CAPE, compared to NODUST. This larger stock of potential energy could allow long-lived MCSs to be more organized (larger, longer lived, and individually more precipitating) in DUST than in NODUST. The significantly reduced number of longlived MCSs drives the total precipitation drop in DUST.

\section{b. Environmental conditions}

The environmental characteristics of the long-lived MCSs $6 \mathrm{~h}$ before their detection are shown in Fig. 14 for the ECMWF analyses and the 3-h forecasts and for the two simulations over the three subregions. These characteristics are examined to understand the drivers of the regional differences in the long-lived MCSs for each dataset and how they are linked to the differences in precipitation production between DUST and NODUST.

For the observed long-lived MCSs, moisture taken from the ECMWF analysis and forecasts is greatest close to the surface and decreases quickly with height in all subregions. At the surface, the water vapor mixing ratio is the largest over SWA $\left(16 \mathrm{~g} \mathrm{~kg}^{-1}\right)$, compared to CAF $\left(15.5 \mathrm{~g} \mathrm{~kg}^{-1}\right)$ and ETH $\left(14 \mathrm{~g} \mathrm{~kg}^{-1}\right)$. The vertical gradient of the equivalent temperature $\theta_{e}$ is the most pronounced over SWA as well, with a variation of approximately $24 \mathrm{~K}$ from the surface $(353 \mathrm{~K})$ to an altitude of approximately $4 \mathrm{~km}(329 \mathrm{~K})$, indicating that the conditional instability is the largest there. This is consistent with the long-lived MCSs being more organized and more highly precipitating over SWA than over CAF or ETH.

The speed of the AEJ, whose core is located near an altitude of $4 \mathrm{~km}$, increases from east to west, from ETH $\left(8 \mathrm{~m} \mathrm{~s}^{-1}\right)$ to SWA $\left(16 \mathrm{~m} \mathrm{~s}^{-1}\right)$, in agreement with the westward enhancement of the propagation speed of the long-lived MCSs (Fig. 13). Therefore, the vertical wind shear that is established due to the AEJ and the low-level south-southwesterly monsoon flow also strengthens over SWA, which helps the long-lived MCSs become more organized there, compared to CAF or ETH.

Both DUST and NODUST simulate the westward increase in the near-surface moisture, the vertical gradient of $\theta_{e}$, and the speed of the AEJ (and associated low-level wind shear) well. The profiles of the water vapor mixing ratio and $\theta_{e}$ over CAF and ETH are nearly identical for the two simulations. Over SWA, both the water vapor mixing ratio and $\theta_{e}$ are larger for DUST than for NODUST up to an altitude of $4 \mathrm{~km}$. For example, at a height of $2 \mathrm{~km}$, DUST is $1 \mathrm{~g} \mathrm{~kg}^{-1}$ wetter and $3 \mathrm{~K}$ warmer. The presence of dust acts to stabilize the lower atmosphere in DUST. In turn, this more stable atmosphere acts to block the entrainment of the surrounding dry air (Parker 2002). The 1-K difference in $\theta_{e}$ near the surface is consistent with the tendency of DUST to have higher values of CAPE, compared to NODUST. Over SWA, the profiles of the wind speed show an AEJ that is located $\sim 500 \mathrm{~m}$ higher for DUST than for NODUST, which is consistent with 

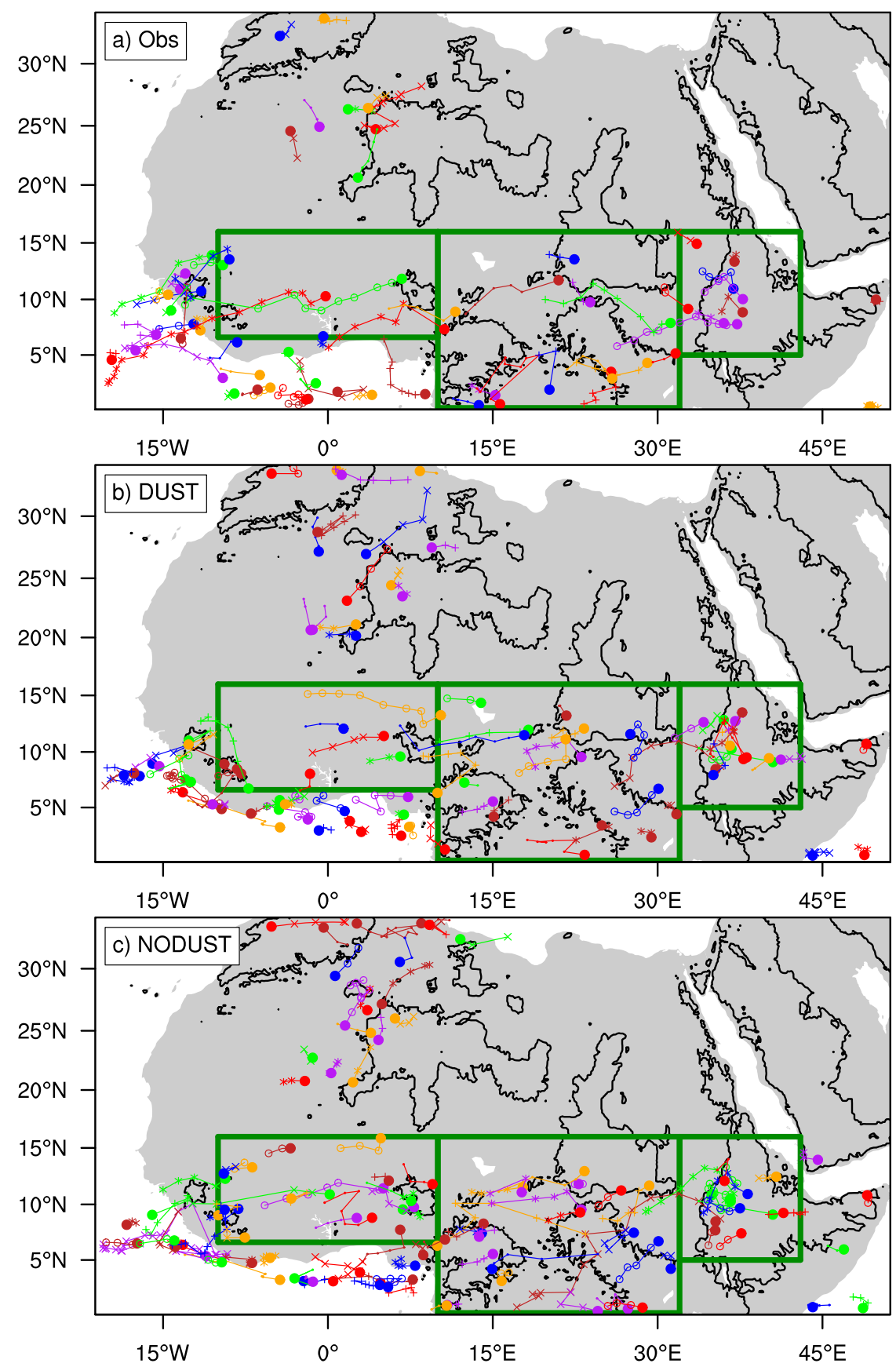

FIG. 12. Trajectories of long-lived MCSs (lifetime of $6 \mathrm{~h}$ or more) for (a) the observations, (b) DUST, and (c) NODUST. The dots represent the first detection of each long-lived MCS. The solid black lines represent the orography at an altitude of $600 \mathrm{~m}$.

Fig. 7, and an enhanced monsoon flow, in agreement with Figs. 8 and 9.

\section{c. Properties of the long-lived MCSs}

The profiles of different properties related to the convective activity inside the long-lived MCSs are investigated at the time of detection (Fig. 15). For both simulations, liquid hydrometeors are present up to the freezing level, at approximately $3-4 \mathrm{~km}$, with a drastic reduction at higher altitudes. A small amount of supercooled water is present up to $7 \mathrm{~km}$, before the cloud droplets freeze completely. The solid hydrometeor content 

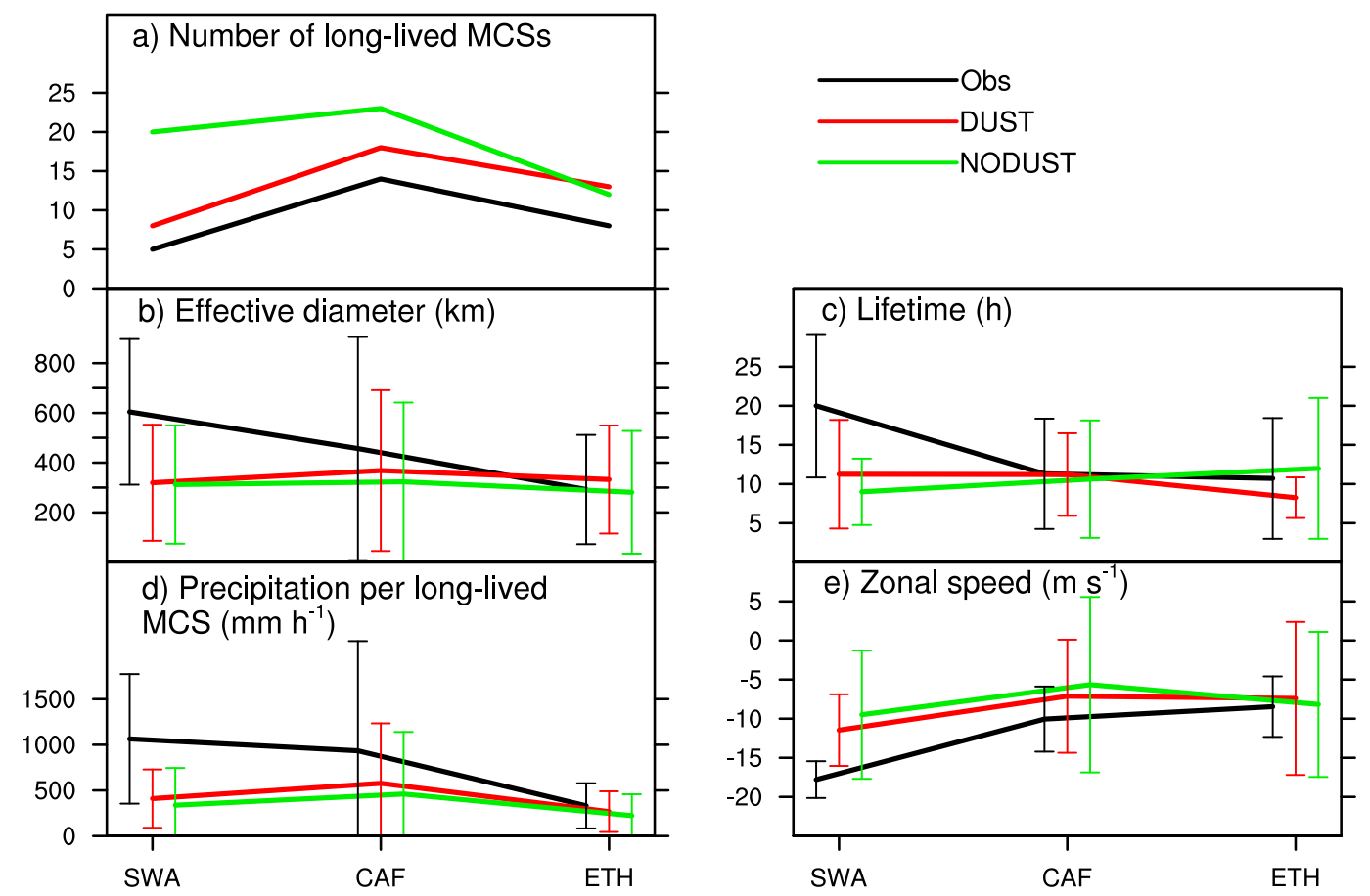

FIG. 13. Characteristics of long-lived MCSs by subregion (SWA, CAF, and ETH) for the observations and the simulations: (a) number of long-lived MCSs, (b) effective diameter, (c) lifetime, (d) precipitation per long-lived MCS, and (e) zonal speed. (b)-(e) Solid lines represent the mean values, and the error bars represent the standard deviation.

increases above the freezing level and reaches a maximum at approximately $9 \mathrm{~km}$. The 99 th percentile of the upward speed has its largest values between 6 and $9 \mathrm{~km}$. The freezing of the liquid particles and deposition of water vapor releases large amounts of latent heat. This renders the air parcels more buoyant, which, in turn, increases their upward velocities inside the updrafts. In the near surface, the drop in $\theta_{e}$ between the time of the detection of the long-lived MCSs and $6 \mathrm{~h}$ before their occurrence is usually a signature of cold pools because the convective downdrafts generated by the evaporative cooling of raindrops transport dry and cold air down to the surface.

Some regional differences in the profiles are evident. Over SWA and CAF, both the hydrometeor loading and the upward velocities are reported to be larger than those over ETH because there is more convective instability (consistent with the distributions of CAPE in Fig. 10). This has an impact on the vertical development of the long-lived MCSs as well. Over SWA and CAF, the freezing level and maximum upward speeds are $1 \mathrm{~km}$ higher than those over ETH. In addition, the hydrometeor content extends to higher altitudes, up to $17 \mathrm{~km}$. For both simulations, $\theta_{e}$ decreases near the surface in the $6 \mathrm{~h}$ prior to convection in all subregions. This decrease becomes more pronounced from ETH to SWA, from approximately 4 to $9 \mathrm{~K}$, indicating that the most intense cold pools occur in SWA.

The profiles also vary between DUST and NODUST. The velocity of the updrafts inside the long-lived MCSs, as well as the hydrometeor content, is larger for DUST in the three subregions. One explanation is that the stabilization of the atmosphere (Fig. 8) results in a larger convective instability for DUST. One consequence of such a stabilization for DUST could be less-diluted updrafts. In terms of the drop in $\theta_{e}$, DUST and NODUST differ the most over SWA (1 K over the lowest $3 \mathrm{~km}$ ). This is consistent with the enhanced convection and propagation speeds of the long-lived MCSs there.

\section{Conclusions}

The radiative impact of dust on precipitation and MCSs over northern Africa is addressed for the period from 9 to 14 June 2006 with the use of two convectionpermitting simulations, one accounting for the radiative effect of dust and the other neglecting this effect. The simulations are evaluated in terms of cloud category and precipitation using satellite observations. To analyze the radiative impact of dust, precipitation is attributed to 

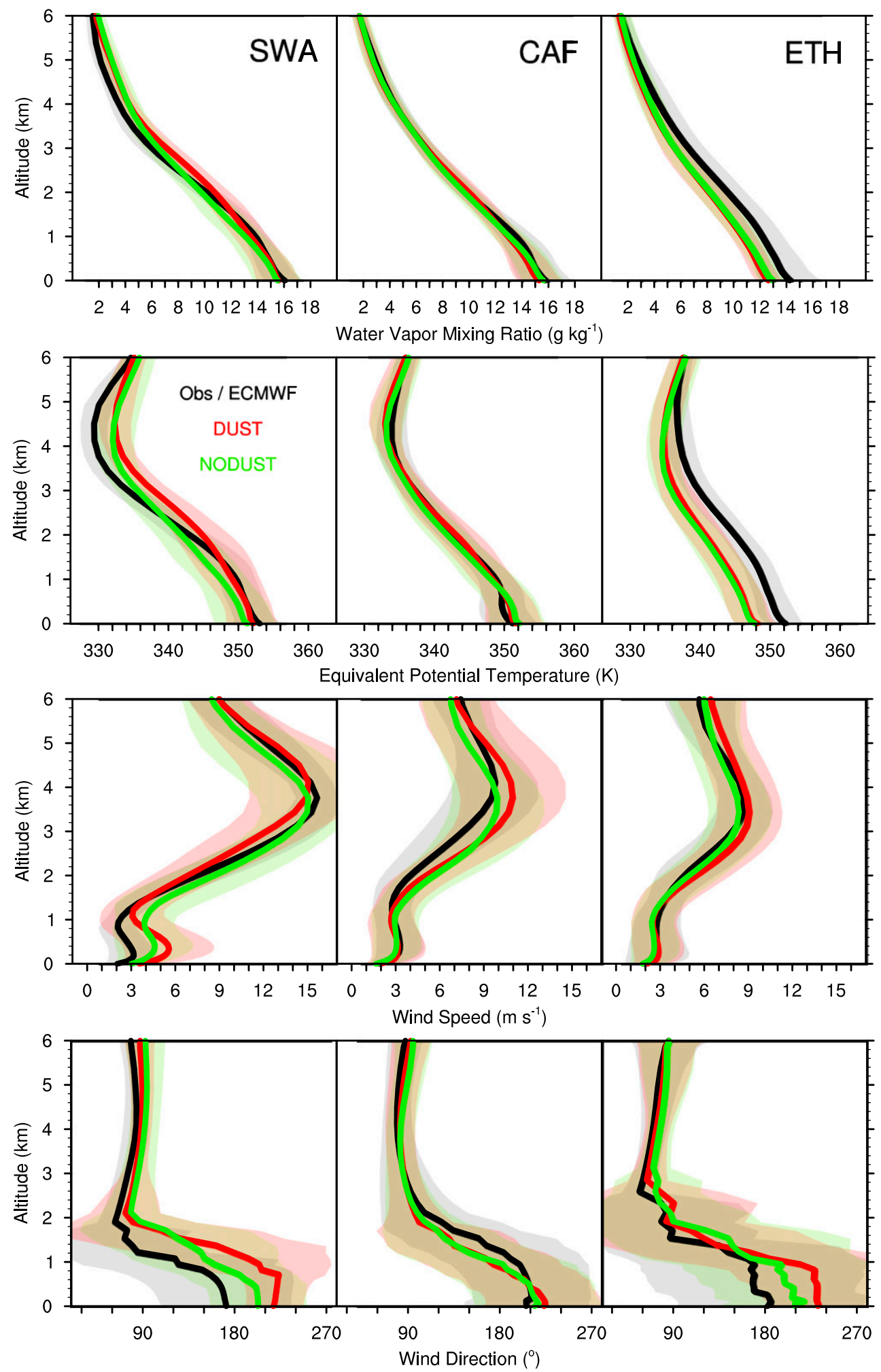

FIG. 14. Mean vertical profiles (from top to bottom) of the water vapor mixing ratio, equivalent potential temperature, wind speed, and wind direction for long-lived MCSs for each subregion: (left) SWA, (middle) CAF, and (right) ETH. The profiles are computed $6 \mathrm{~h}$ before the long-lived MCS detection. The shaded contours represent the standard deviation. 

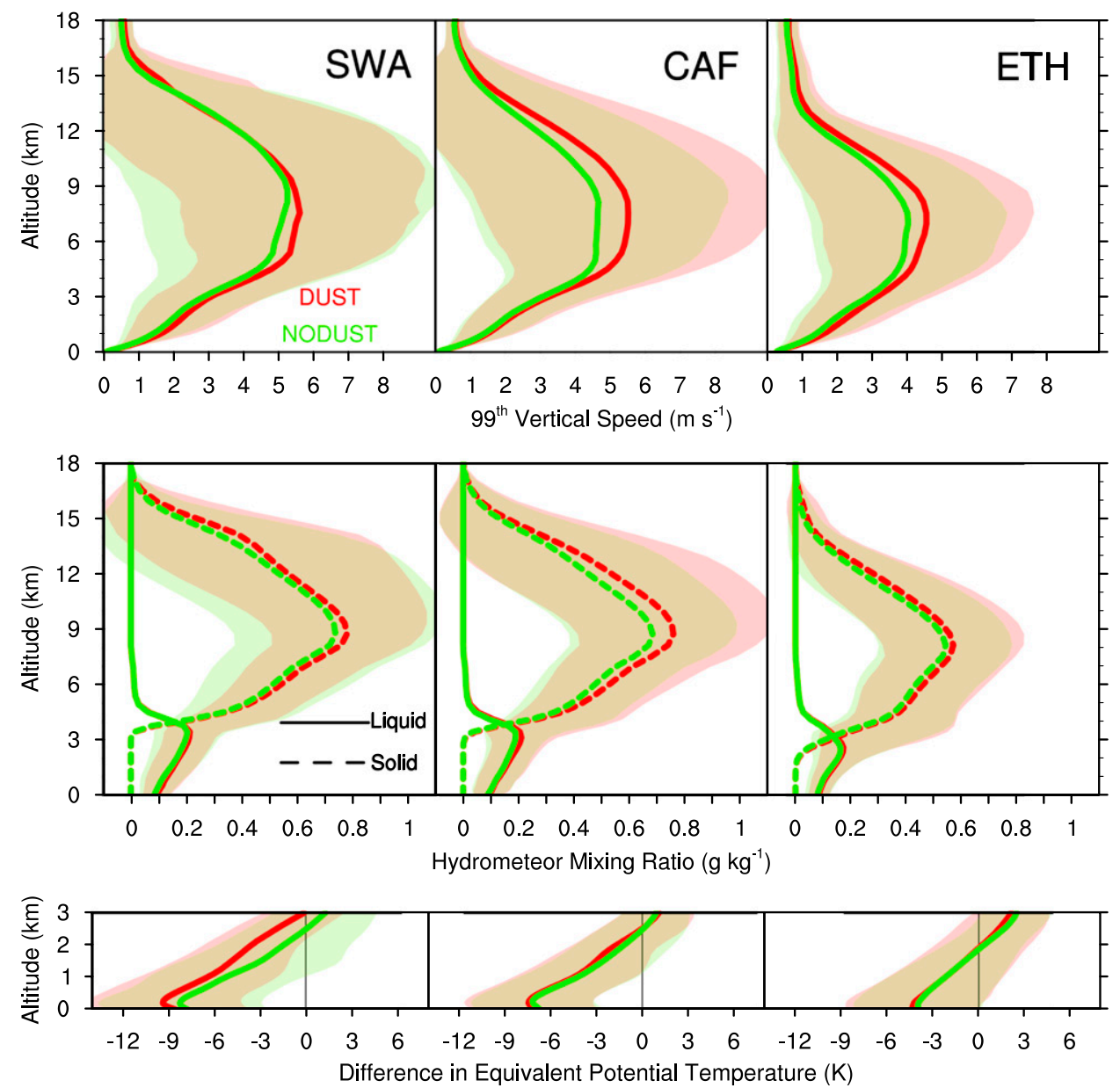

FIG. 15. Mean vertical profiles (from top to bottom) of the 99th percentile of the vertical wind speed, the mean hydrometeor mixing ratio (liquid and solid) for long-lived MCSs at the time of detection, and the difference in the mean equivalent temperature inside the long-lived MCS and at the same location $6 \mathrm{~h}$ before for (left) SWA, (middle) CAF, and (right) ETH. The shaded contours represent the standard deviation.

different cloud categories such as MCSs, which are then tracked and examined over the three continental subregions of southern West Africa, central Africa, and Ethiopia. This method is applied in the same manner to the two simulations and to the satellite observations. Both simulations show a realistic spatial distribution of precipitation when compared to the observations and capture the observed distribution of precipitation between the different cloud categories. The most organized and propagative MCSs account for the majority of the precipitation (approximately half of the total precipitation). The contribution to the precipitation of the other cloud types does not vary between the simulations.

An assessment of the simulations against the satellite and AERONET measurements shows that the simulation with dust-radiation interaction simulates the horizontal distribution and the vertical stratification of dust well and that the values of AOD are well represented and only slightly underestimated at the stations with the southwestern-most locations. This makes us confident that we can investigate the dust effects on the atmosphere based on a comparison of simulations with and without dust. A mean warming of $1.3 \mathrm{~K}$ is observed for the dust simulation between altitudes of 3 and $5 \mathrm{~km}$, where the dust loads are at their maximum. These results are consistent with those obtained by Lemaitre et al. (2010). A near-surface cooling is linked with the northern displacement of the intertropical discontinuity in the presence of dust, leading to an increase of moisture over land. Over the ocean, the intertropical convergence zone is shifted northward, modifying the distribution of precipitation. The perturbation of 
the temperature field and its meridional gradient is at the origin of the reported AEJ intensification of $1-2 \mathrm{~m} \mathrm{~s}^{-1}$ over southern West Africa. There, the midlevel warming and surface cooling are the most pronounced of the three subregions.

In tropical northern Africa, where strong sensible heat fluxes render the first layers of the atmosphere convectively unstable, the thermodynamics at low levels is pivotal for the triggering of convection. In the simulation with dust, the increase in the vertical gradient of the temperature leads to the stabilization of the lower atmosphere, as found by Tulet et al. (2008). Consequently, the triggering of long-lived MCSs (with lifetimes of at least $6 \mathrm{~h}$ ) is reduced over southern West Africa. Their number decreases to one-third of the population that is simulated in the absence of dust-radiation interaction; therefore, the precipitation due to long-lived MCSs is greatly diminished, driving an overall drop in the total precipitation in that subregion.

When taking into account the radiative effects of dust, the long-lived MCSs are found to last a little longer, to be more efficient in terms of precipitation production, and to be more propagative. In other words, they are slightly more organized. Two factors play a role in helping the long-lived MCSs become more organized in the dust simulation. First, the acceleration of the AEJ drives an increase in the associated vertical low-level wind shear, a fundamental dynamical feature needed to maintain the MCSs (Laing et al. 2008; Reinares Martínez and Chaboureau 2018). Second, the simulation accounting for the radiative effect of dust was diagnosed as having a reservoir of CAPE greater than that of the simulation neglecting the radiative effect of dust; this energy was stored as a result of the inhibition of convective triggering. This energy is released when a long-lived MCS develops, leading to more intense convective activity, consistent with the increased degree of organization of the systems, and confirmed by the presence of faster updrafts and larger hydrometeor loadings within the clouds.

The results found here are sensitive to the description of dust in the model. Several uncertainties arise from emission, transport, and deposition, which affect the spatial distribution and lifetime of the dust particles. The results are also dependent on the optical properties of dust. Accurately constraining these processes in the model would lead to more realistic radiative dust effects. The microphysical dust-cloud interaction (the indirect effect of dust) is beyond the scope of this study but needs to be addressed. Dust particles are efficient ice nuclei, providing a substrate for ice initiation, which may drive changes in precipitation. Finally, the analysis performed here is restricted to a single 6-day period with large concentrations of dust. It would be worthwhile to repeat this analysis for other dusty cases. Extending this analysis to longer periods may also allow the conclusions found in this article to be generalized.

Acknowledgments. The research leading to these results has received funding from the European Union 7th Framework Program (FP7/2007-2013) under Grant Agreement 603502 (EU Project DACCIWA: Dynamicsaerosol-chemistry-cloud interactions in West Africa). Computer resources were allocated by GENCI through Project 90569. We thank the anonymous reviewers for their comments, which helped to improve the overall quality of the paper.

\section{REFERENCES}

Chaboureau, J.-P., and P. Bechtold, 2005: Statistical representation of clouds in a regional model and the impact on the diurnal cycle of convection during Tropical Convection, Cirrus and Nitrogen Oxides (TROCCINOX). J. Geophys. Res., 110, D17103, https://doi.org/10.1029/2004JD005645.

_, P. Tulet, and C. Mari, 2007: Diurnal cycle of dust and cirrus over West Africa as seen from Meteosat Second Generation satellite and a regional forecast model. Geophys. Res. Lett., 34, L02822, https://doi.org/10.1029/2006GL027771.

__ , and Coauthors, 2008: A midlatitude precipitating cloud database validated with satellite observations. J. Appl. Meteor. Climatol., 47, 1337-1353, https://doi.org/10.1175/ 2007JAMC1731.1.

_ , and Coauthors, 2011: Long-range transport of Saharan dust and its radiative impact on precipitation forecast: A case study during the Convective and Orographically-induced Precipitation Study (COPS). Quart. J. Roy. Meteor. Soc., 137, 236-251, https://doi.org/10.1002/qj.719.

_ over the Sahara in June 2011. Atmos. Chem. Phys., 16, 69776995, https://doi.org/10.5194/acp-16-6977-2016.

Crumeyrolle, S., and Coauthors, 2011: Transport of dust particles from the Bodélé region to the monsoon layer-AMMA case study of the 9-14 June 2006 period. Atmos. Chem. Phys., 11, 479-494, https://doi.org/10.5194/acp-11-479-2011.

Cuxart, J., P. Bougeault, and J.-L. Redelsperger, 2000: A turbulence scheme allowing for mesoscale and large-eddy simulations. Quart. J. Roy. Meteor. Soc., 126, 1-30, https://doi.org/ 10.1002/qj.49712656202.

Engelstaedter, S., I. Tegen, and R. Washington, 2006: North African dust emissions and transport. Earth-Sci. Rev., 79, 73100, https://doi.org/10.1016/j.earscirev.2006.06.004.

Flamant, C., J.-P. Chaboureau, D. J. Parker, C. M. Taylor, J.-P. Cammas, O. Bock, F. Timouk, and J. Pelon, 2007: Airborne observations of the impact of a convective system on the planetary boundary layer thermodynamics and aerosol distribution in the inter-tropical discontinuity region of the West African Monsoon. Quart. J. Roy. Meteor. Soc., 133, 1175-1189, https://doi.org/10.1002/qj.97.

— C. Cavaysse, M. Todd, J.-P. Chaboureau, and J. Pelon, 2009: Multi-platform observations of a springtime case of Bodélé and Sudan dust emission, transport and scavenging over West Africa. Quart. J. Roy. Meteor. Soc., 135, 413-430, https:// doi.org/10.1002/qj.376. 
Fouquart, Y., and B. Bonnel, 1980: Computations of solar heating of the Earth's atmosphere-A new parametrization. Beitr. Phys. Atmos., 53, 35-62.

Grini, A., P. Tulet, and L. Gomes, 2006: Dusty weather forecasts using the MesoNH mesoscale atmospheric model. J. Geophys. Res., 111, D19205, https://doi.org/10.1029/ 2005JD007007.

Helmert, J., B. Heinold, I. Tegen, O. Hellmuth, and M. Wendisch, 2007: On the direct and semidirect effects of Saharan dust over Europe: A modeling study. J. Geophys. Res., 112, D13208, https://doi.org/10.1029/2006JD007444.

Holben, B. N., and Coauthors, 1998: AERONET - A federated instrument network and data archive for aerosol characterization. Remote Sens. Environ., 66, 1-16, https://doi.org/ 10.1016/S0034-4257(98)00031-5.

Hsu, N. C., S.-C. Tsay, M. D. King, and J. R. Herman, 2004: Aerosol properties over bright-reflecting source regions. IEEE Trans. Geosci. Remote Sens., 42, 557-569, https:// doi.org/10.1109/TGRS.2004.824067.

Huffman, G. J., and Coauthors, 2007: The TRMM Multisatellite Precipitation Analysis (TMPA): Quasi-global, multiyear, combined-sensor precipitation estimates at fine scales. $J$. $\mathrm{Hy}$ drometeor., 8 (1), 38-55, https://doi.org/10.1175/JHM560.1.

Janiga, M. A., and C. D. Thorncroft, 2014: Convection over tropical Africa and the East Atlantic during the West African Monsoon: Regional and diurnal variability. J. Climate, 27, 41594188, https://doi.org/10.1175/JCLI-D-13-00449.1.

Janowiak, J. E., R. J. Joyce, and Y. Yarosh, 2001: A real-time global half-hourly pixel-resolution infrared dataset and its applications. Bull. Amer. Meteor. Soc., 82, 205-218, https:// doi.org/10.1175/1520-0477(2001)082<0205:ARTGHH >2.3. $\mathrm{CO} ; 2$.

Lac, C., and Coauthors, 2018: Overview of the Meso-NH model version 5.4 and its applications. Geosci. Model Dev., 11, 19291969, https://doi.org/10.5194/gmd-11-1929-2018.

Lafore, J. P., and Coauthors, 1998: The Meso-NH Atmospheric Simulation System. Part I: Adiabatic formulation and control simulations. Ann. Geophys., 16, 90-109, https://doi.org/ 10.1007/s00585-997-0090-6

Laing, A. G., R. Carbone, V. Levizzani, and J. Tuttle, 2008: The propagation and diurnal cycles of deep convection in northern tropical Africa. Quart. J. Roy. Meteor. Soc., 134, 93-109, https://doi.org/10.1002/qj.194.

Lemaître, C., C. Flamant, J. Cuesta, J.-C. Raut, P. Chazette, P. Formenti, and J. Pelon, 2010: Radiative heating rates profiles associated with a springtime case of Bodélé and Sudan dust transport over West Africa. Atmos. Chem. Phys., 10, 8131-8150, https://doi.org/10.5194/acp-10-8131-2010.

Marticorena, B., and G. Bergametti, 1995: Modeling the atmospheric dust cycle: 1 . Design of a soil-derived dust emission scheme. J. Geophys. Res., 100, 16415-16430, https://doi.org/ 10.1029/95JD00690.

Masson, V., and Coauthors, 2013: The SURFEXv7.2 land and ocean surface platform for coupled or offline simulation of Earth surface variables and fluxes. Geosci. Model Dev., 6, 929 960, https://doi.org/10.5194/gmd-6-929-2013.

Mathon, V., H. Laurent, and T. Lebel, 2002: Mesoscale convective system rainfall in the Sahel. J. Appl. Meteor., 41, 1081-1092, https://doi.org/10.1175/1520-0450(2002)041<1081:MCSRIT>2.0. $\mathrm{CO} ; 2$.
Mlawer, E. J., S. J. Taubman, P. D. Brown, M. J. Iacono, and S. A. Clough, 1997: Radiative transfer for inhomogeneous atmospheres: RRTM, a validated correlated-k model for the longwave.J. Geophys. Res., 102, 16663-16 682, https://doi.org/ 10.1029/97JD00237.

Noilhan, J., and S. Planton, 1989: A simple parameterization of land surface processes for meteorological models. Mon. Wea. Rev., 117, 536-549, https://doi.org/10.1175/1520-0493(1989) $117<0536$ :ASPOLS $>2.0 . \mathrm{CO} ; 2$.

Parker, D. J., 2002: The response of CAPE and CIN to tropospheric thermal variations. Quart. J. Roy. Meteor. Soc., 128, 119-130, https://doi.org/10.1256/00359000260498815.

Pérez, C., S. Nickovic, G. Pejanovic, J. M. Baldasano, and E. Özsoy, 2006: Interactive dust-radiation modeling: A step to improve weather forecasts. J. Geophys. Res., 111, D16206, https://doi. org/10.1029/2005JD006717.

Pergaud, J., V. Masson, S. Malardel, and F. Couvreux, 2009: A parameterization of dry thermals and shallow cumuli for mesoscale numerical weather prediction. Bound.-Layer Meteor., 132, 83-106, https://doi.org/10.1007/s10546-009-9388-0.

Pinty, J.-P., and P. Jabouille, 1998: A mixed-phase cloud parameterization for use in a mesoscale non-hydrostatic model: Simulations of a squall line and of orographic precipitations. Conf. on Cloud Physics, Everett, WA, Amer. Meteor. Soc., 217-220.

Reinares Martínez, I., and J.-P. Chaboureau, 2018: Precipitation and mesoscale convective systems: Explicit versus parameterized convection over northern Africa. Mon. Wea. Rev., 146, 797-812, https://doi.org/10.1175/MWR-D-17-0202.1.

Saunders, R., M. Matricardi, P. Brunel, S. English, P. Bauer, U. O'Keeffe, P. Francis, and P. Rayer, 2005: RTTOV8-Science and validation report. NWP SAF Tech. Rep., 41 pp., https://nwpsaf.eu/oldsite/deliverables/rtm/rttov8_svr.pdf.

Tompkins, A. M., C. Cardinali, J.-J. Morcrette, and M. Rodwell, 2005: Influence of aerosol climatology on forecasts of the African Easterly Jet. Geophys. Res. Lett., 32, L10801, https:// doi.org/10.1029/2004GL022189.

Tulet, P., V. Crassier, F. Cousin, K. Suhre, and R. Rosset, 2005: ORILAM, a three-moment lognormal aerosol scheme for mesoscale atmospheric model: Online coupling into the Meso-NH-C model and validation on the Escompte campaign. J. Geophys. Res., 110, D18201, https://doi.org/10.1029/ 2004JD005716.

, M. Mallet, V. Pont, J. Pelon, and A. Boone, 2008: The 713 March 2006 dust storm over West Africa: Generation, transport, and vertical stratification. J. Geophys. Res., 113, D00C08, https://doi.org/10.1029/2008JD009871.

Winker, D. M., M. A. Vaughan, A. Omar, Y. Hu, K. A. Powell, Z. Liu, W. H. Hunt, and S. A. Young, 2009: Overview of the CALIPSO mission and CALIOP data processing algorithms. J. Atmos. Oceanic Technol., 26, 2310-2323, https://doi.org/ 10.1175/2009JTECHA1281.1.

Zender, C. S., H. Bian, and D. Newman, 2003: Mineral Dust Entrainment and Deposition (DEAD) model: Description and 1990s dust climatology. J. Geophys. Res., 108, 4416, https:// doi.org/10.1029/2002JD002775.

Zhang, G., K. H. Cook, and E. K. Vizy, 2016: The diurnal cycle of warm season rainfall over West Africa. Part I: Observational analysis. J. Climate, 29, 8423-8437, https://doi.org/10.1175/ JCLI-D-15-0874.1. 